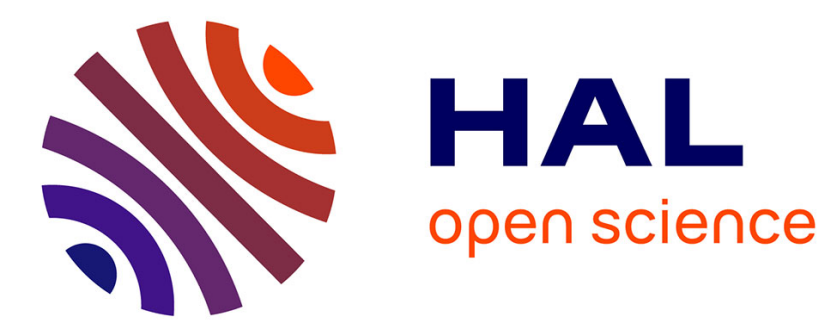

\title{
Modelling the interplate domain in thermo-mechanical simulations of subduction: Critical effects of resolution and rheology, and consequences on wet mantle melting
}

Diane Arcay

\section{- To cite this version:}

Diane Arcay. Modelling the interplate domain in thermo-mechanical simulations of subduction: Critical effects of resolution and rheology, and consequences on wet mantle melting. Physics of the Earth and Planetary Interiors, 2017, 269, pp.112-132. 10.1016/j.pepi.2017.05.008 . hal-01623155

\section{HAL Id: hal-01623155 \\ https://hal.science/hal-01623155}

Submitted on 25 Sep 2020

HAL is a multi-disciplinary open access archive for the deposit and dissemination of scientific research documents, whether they are published or not. The documents may come from teaching and research institutions in France or abroad, or from public or private research centers.
L'archive ouverte pluridisciplinaire HAL, est destinée au dépôt et à la diffusion de documents scientifiques de niveau recherche, publiés ou non, émanant des établissements d'enseignement et de recherche français ou étrangers, des laboratoires publics ou privés. 


\title{
Modelling the interplate domain in thermo-mechanical simulations of subduction: Critical effects of resolution and rheology, and consequences on wet mantle melting
}

\author{
Diane Arcay ${ }^{\mathrm{a}, *}$ \\ ${ }^{a}$ Geosciences Montpellier, CNRS, Université de Montpellier, Université des Antilles, \\ UMR5243, Place E. Bataillon, bât. 22, cc060, 34095 Montpellier cedex 05, France \\ phone: +33467144281, fax: +33467143642.
}

\begin{abstract}
The present study aims at better deciphering the different mechanisms involved in the functioning of the subduction interplate. A 2D thermo-mechanical model is used to simulate a subduction channel, made of oceanic crust, free to evolve. Convergence at constant rate is imposed under a $100 \mathrm{~km}$ thick upper plate. Pseudo-brittle and non-Newtonian behaviours are modelled. The influence of the strength contrast modelling the subduction channel, represented by the difference in activation energy between crust and mantle $\left(\Delta E_{a}\right)$ is investigated to examine in detail the variations in depth of the subduction plane down-dip extent, $z_{\text {coup }}$. First, simulations show that numerical resolution may be responsible for an artificial and significant shallowing of $z_{\text {coup }}$ if the weak crustal layer is not correctly discretized. Second, if the age of the subducting plate is $100 \mathrm{Myr}$, subduction occurs for any strength reduction $\Delta E_{a}$. The stiffer the crust is, the shallower $z_{\text {coup }}$ is $\left(60 \mathrm{~km}\right.$ depth if $\left.\Delta E_{a}=20 \mathrm{~kJ} / \mathrm{mol}\right)$ and the hotter the fore-arc base is. Conversely, imposing a very weak subduction channel $\left(\Delta E_{a}>135 \mathrm{~kJ} / \mathrm{mol}\right)$ leads to an extreme mantle wedge cooling and inhibits mantle melting in wet conditions. Partial kinematic coupling at the fore-arc base occurs if $\Delta E_{a}=145 \mathrm{~kJ} / \mathrm{mol}$. If the incoming plate is $20 \mathrm{Myr}$ old, subduction can occur if the crust is either stiff and denser than the mantle, or weak and buoyant. In the latter case cold crust plumes rise from the subduction channel and ascend through the upper lithosphere, triggering (1) partial kinematic coupling at the fore-arc base, (2) fore-arc lithosphere cooling, and (3) partial or complete hindrance of wet mantle melting. $z_{\text {coup }}$ then ranges from 50 to more than $250 \mathrm{~km}$ depth and is time-dependent if crust plumes form. Finally, subduction plane dynamics is intimately linked to the regime of subduction-induced corner flow. Two different intervals of $\Delta E_{a}$ are underlined: $80-120 \mathrm{~kJ} / \mathrm{mol}$ to reproduce the range of slab surface temperature inferred from geothermometry, and $10-40 \mathrm{~kJ} / \mathrm{mol}$ to reproduce the shallow hot mantle wedge core inferred
\end{abstract}

\footnotetext{
* Corresponding author

Email address: diane.arcay@gm.univ-montp2.fr (Diane Arcay)
} 
from conditions of last equilibration of near-primary arc magmas and seismic tomographies. Therefore, an extra process controlling mantle wedge dynamics is needed to satisfy simultaneously the aforementioned observations. A mantle viscosity reduction, by a factor 4 to 20 , caused by metasomatism in the mantle wedge is proposed. From these results, I conclude that the subduction channel down-dip extent should depend on the subduction setting, in agreement with the observed variability of sub-arc depths of the subducting plate surface. $r$

Keywords: subduction interface, thermo-mechanical modelling, rheology, numerical resolution, oceanic crust buoyancy, wet mantle partial melting

\section{Introduction}

The mantle wedge tip and subduction plane are key structures of the subduction factory, affecting not only the subduction viability but also seismogenic properties of the subduction plane, fluid transfers, and melt migration towards the volcanic arc (Fig. 1). Using a thermo-kinematic model applied in 17 subduction zones constrained by heat flux profiles, Wada and Wang (2009) suggested that the Maximum Depth of kinematic Decoupling (MDD) along the subduction plane was constant for all considered subduction zones and equal to $80 \mathrm{~km}$ depth, the process controling it remaining to be determined. Other observations advocate on the contrary for a certain degree of variability, as indicated for instance by the depth to slab under volcanic front ("sub-arc slab depth", Fig. 1) : $110 \pm 20 \mathrm{~km}$ in Jarrard (1986), varying more broadly in recent studies: 60-120 km depth in England and Wilkins (2004) and 70-170 km in Syracuse and Abers (2006). Even if the average sub-arc slab depth is always centered at $105 \mathrm{~km}$, corresponding to the most frequent overlapping plate thickness (Heuret and Lallemand, 2005), the volcanic arc location may vary as a function of convergence parameters, even if the exact governing process is debated (Grove et al., 2009; England and Katz, 2010). To assess the exact MDD, heat flow data are useful: from a minimum at trench, heat flux increases landwards to a maximum plateau assumed to start right above the MDD (Honda, 1985; Furukawa, 1993). Nonetheless, the assertion by Wada and Wang (2009) of a MDD uniformly equal to $80 \mathrm{~km}$ depth is based on heat-flow data presenting either an extremely low spatial density or a significant scattering. Even if the down-dip extent of subduction planes might actually be located at $80 \mathrm{~km}$ depth for all subduction zones, the observations used to state it are not completely convincing yet, whereas the variability of well-constrained sub-arc slab depths is meaningful. In any case, the processes regulating the subduction plane geometry have to be better understood.

Notable progress have been made in understanding the subduction plane dynamics. On one hand, van Keken et al. (2002) using thermo-kinematic models showed that modelling a temperature- and stress-dependent viscosity drastically increased thermal gradients at the slab surface. Wada et al. (2008) and Hirauchi and Katayama (2013) showed that the formation of low-temperature hydrated 
minerals such as serpentine in the thermal boundary layer covering the subducting slab reduces viscous couplings between slab and asthenosphere and cools the mantle wedge. Thermo-kinematic models have been pointed out by geochemists studying mantle melting at the slab surface (e.g., Kelemen et al., 2003; Plank et al., 2009; Grove et al., 2012; Cooper et al., 2012, Fig. 1), this because simulated slab surfaces are hotter than obtained in thermo-mechanical models, in better agreement with geochemical analyses. The cause likely comes from the prescribed rigid lid within the upper plate that partly includes the underneath low viscosity wedge, which should otherwise flow onto the slab surface (Arcay et al., 2007b; Wada and King, 2015), and cool it. Conder (2005) proposed a parameterization of the subduction fault taking into account temperature- and strain-rate dependence to limit the arbitrariness of the imposed rigid lid thickness. Moreover, partial kinematic coupling has been assumed to occur at the fore-arc base (Kneller et al., 2005, 2007; van Keken et al., 2011), i.e., velocities in the thin layer covering the down-dip extent of the subduction channel would be much lower than corner flow velocity, typically about a few percents of subduction speed (Fig. 1). The origin of partial kinematic coupling being unclear, a possible explanation is proposed in this paper.

On the other hand, thermo-mechanical models showed that if the subduction plane was free to evolve its structure (depth of brittle-ductile transition and MDD) depended on the modelled brittle rheology and on ductile strength, as well as on subduction speed and age at trench of the subducting plate (Arcay et al., 2006; Arcay, 2012). However, the influence of interplate rheology, addressed by Wada et al. (2008) by imposing the MDD, has not been completely established in a self-consistent model, although interactions between interplate shearing and corner flow dynamics may be crucial to regulate the subduction interplate. This motivates the present study. In thermo-mechanical models, the tangential velocity discontinuity along the subduction interface (Fig. 1) is classically modelled by a thin layer weaker than the surrounding mantle by several orders of magnitude (e.g., Kopitzke, 1979; Gurnis and Hager, 1988; King and Hager, 1990; Gerya et al., 2008; Quinquis et al., 2011; Agrusta et al., 2014; Garel et al., 2014; Crameri and Tackley, 2015; Marques and Kaus, 2016). A similar set-up is used in this paper to study carefully how the subduction channel geometry is regulated and how its strength affects the global subduction zone structure. As the subduction plane is likely to equilibrate at the time-scale of tens of Myr, long-term experiments are performed ( 20 to $40 \mathrm{Myr}$ of convergence). If the upper plate is thick $(\sim 100 \mathrm{~km})$, forming a viable subduction channel is tough when the incoming plate is young and buoyant (Arcay, 2012). That is why the oceanic crust density will also have to be tested when modelling a young plate subduction. Results show that modifying both the subduction channel strength and density generates a broad variety of subduction regimes. At last, as numerical resolution can be critical (Schmeling et al., 2008), it has to be investigated. These different reasons finally yield a long study but, I hope, consistent. The paper starts with a short summary of key processes implied in the functioning of a subduction interplate. Then, the model set-up is described. Next, the strong influence of numerical resolution is detailed first. Afterwards, 
the paper presents what kind of thermal structure is obtained in the vicinity of the subduction plane down-dip extent as a function of rheology for two endmember subducting plate ages at trench (either $100 \mathrm{Myr}$, section 5.1, or 20 Myr, section 5.2). The case of an middle age incoming plate (60 Myr) is briefly described to derive a comprehensive regime diagram at the end of the result section. Three types of outputs are described: (1) depth of maximum decoupling along the interplate and velocity field in the mantle wedge, (2) subduction viability, and (3) prediction of wet mantle melting. This study shows that the subduction plane structure and extent are intimately linked to the regime of the subduction-induced corner flow in the asthenosphere. In the last part of the paper, by combining modelling outputs with two main observations typically used to discuss the mantle wedge thermal state (pressure-temperature conditions at the slab surface and spatial extent of the cold fore-arc nose), the range of realistic ductile strength to impose along the subduction plane will be discussed. To conclude, the study argues for an interplate decoupling depth dependent on the subduction setting and likely to vary from a subduction zone to another.

\section{Subduction interplate functioning inferred from previous studies}

To sustain subduction, the interplate channel has to allow simultaneously for two opposite processes (Arcay, 2012). On the one hand, the velocity discontinuity at shallow depth is maintained by a highly localized shearing (Fig. 1). Strain localization depends on the strength contrast between the soft crustal layer and the surrounding mantle. On the other hand, next to the upper plate base, localized strain has to jump from the subduction channel to the asthenosphere to thermally decouple converging plates (Doin and Henry, 2001). This occurs if the subduction channel is stiffer than hot asthenosphere. Reversely, if the subduction channel is not significantly weak, the asthenospheric flow focussing at mantle wedge tip is needed to mechanically separate converging plates. This phenomenon was well exemplified by Eberle et al. (2002). If the subduction fault is modeled solely by a kinematic boundary condition, and not mechanically (such as by low stress or viscosity condition), when a no-slip condition is imposed on top surface, then the asthenosphere rises along the subduction plane up to $z \sim 0$. Indeed, the only means for the flow to satisfy the two kinematic conditions is to propel the weak asthenosphere along the kinematic fault, up to the surface. In this case the asthenosphere acts as the missing decoupling agent. On the contrary, a very weak subduction channel, and/or the absence of corner flow formation prevent localized strain from jumping towards the asthenospheric wedge tip. As a result, the continuous localization of convergence within the weak interplate channel yields horizontal subduction, as modelled for a young and rather buoyant subducting lithosphere (Arcay, 2012).

\section{Model set-up}

Simulations are performed in 2D by solving the equations of mass, momentum, and energy conservation, using the thermo-chemico-mechanical code of 
Christensen (1992), based on spline-finite elements on an Eulerian grid. Fluid incompressibility is assumed except in the momentum equation. A uniform volumetric heating, as well as shear heating and adiabatic heating are included in the energy equation (extended Boussinesq approximation). Compositional tracers, with specific density and rheology, are advected as a function of the velocity field (fourth order Runge-Kutta scheme, van Keken et al., 1997).

\subsection{Boundary conditions and initial state}

The 2D simulation box, $2220 \mathrm{~km}$ wide and $555 \mathrm{~km}$ deep, is filled with two different lithologies: a $\sim 7 \mathrm{~km}$ thick layer overlies the incoming lithosphere, while the rest of the box is made of mantle (Fig. 2). The initial thermal structure of the overriding lithosphere results from a preliminary experiment in which thermal equilibrium between heating from below and cooling from above was performed without plate kinematics, but keeping identical other thermo-mechanical parameters. For simplicity, the upper lithosphere structure is the same for all simulations. A constant convergence rate of $6.5 \mathrm{~cm} / \mathrm{yr}$ is applied on the top surface far away from the subduction zone (Fig. 2). The crust layer covering the incoming plate surface also fills the initial subduction plane whose dip angle is $30^{\circ}$ until $55 \mathrm{~km}$ depth. As crustal rocks are assumed to be significantly weaker than mantle (see below), strain will focus within the initial crustal interplate at convergence start (Fig. 2), triggering plate bending in the vicinity of the trench $(x=1110 \mathrm{~km})$. The thermal, mechanical and compositional structure of the subduction channel is then free to evolve.

To sustain a constant age at trench of the subducting plate, labelled $A_{t}$, a specific thermal condition is imposed in the top left hand corner of the simulation box. A constant plate age is imposed $710 \mathrm{~km}$ away ahead of the trench, by setting on a $400 \mathrm{~km}$ wide domain a plate cooling from asthenosphere outcropping at $x=0$ to thermal thickening corresponding to an oceanic plate age, $A_{\text {lith }}$, reached at $x=400 \mathrm{~km}$ (Fig. 2). As it takes $\sim 11$ Myr for a column of oceanic plate to drift from $x=400 \mathrm{~km}$ to the trench, $A_{l i t h}$ is set to: $A_{l i t h}=A_{t}-11$ (in Myr). Crustal tracers are continuously supplied down to the Moho to renew the layer covering the subducting plate in the top left corner. The Moho depth is either $\sim 7$ or $\sim 8 \mathrm{~km}$ depending on resolution mesh (Table 1). Other kinematical, mechanical, and thermal conditions are summarised in Figure 2.

To estimate the upper plate stress state, the regional horizontal tectonic force, $F_{\text {res }}$, is computed at $x=1665 \mathrm{~km}$ (Fig. 2) from $\sigma_{x x}$ deviation from lithostatic stresses in an oceanic column of density $\rho_{\text {ref }}$ (Christensen, 1992): $F_{\text {res }}=$

$-\int_{0}^{z_{i}} \sigma_{x x} d z+\int_{0}^{z_{i}} \rho_{\text {ref }}(z) g z d z$, where $z_{i}$ is the compensation depth $(278 \mathrm{~km})$ and $\sigma_{x x}$ is the horizontal normal component of stress tensor. $F_{r e s}$ corresponds to the force applied to keep constant convergence velocity.

\subsection{Rheology}

A non-Newtonian viscous rheology and a pseudo-brittle rheology are combined. Strength, for both oceanic crust and mantle rocks. The non-Newtonian 
ductile viscosity, $\nu_{d}$, depending on depth $(z)$, temperature $(T)$, and second invariant of the deviatoric strain rate tensor $(\dot{\varepsilon})$, writes as:

$$
\nu_{d}=A_{0} \exp \left(\frac{E_{a}(C)+V_{a} \rho g z}{n R T}\right) \dot{\varepsilon}^{1 / n-1}
$$

where $A_{0}$ is a pre-exponential factor, $E_{a}$ is the activation energy depending on the lithology $(C), V_{a}$ is the activation volume, $P$ is the lithostatic pressure, $n$ is a exponent higher than $1, \rho$ is the mantle density, $g$ is the gravity acceleration, and $R$ is the ideal gas constant. In the brittle domain, the yield stress, $\tau_{y}$, writes as:

$$
\tau_{y}=\tau_{0}+\gamma(C) \rho g z
$$

where $\tau_{0}$ is the frictional cohesive strength at the surface, $\gamma$ is a parameter related to the friction coefficient (Turcotte and Schubert, 1982) depending on lithology. The brittle strain rate, $\dot{\varepsilon}_{b}$, is defined as a function of stress, $\tau$ : $\dot{\varepsilon}_{b}=$ $\left(\tau / \tau_{y}\right)^{n_{p}} \dot{\varepsilon}_{r e f}$, where $n_{p}$ is a stress exponent higher than 10 and $\dot{\varepsilon}_{r e f}$ is reference strain rate. Using the yield stress and the brittle deformation rate, an equivalent viscosity in the brittle domain, $\nu_{b}$, is defined as:

$$
\nu_{b}=\tau_{y}\left(\frac{\dot{\varepsilon}_{b}^{\frac{1}{n_{p}}}-1}{\dot{\varepsilon}_{r e f}^{\frac{1}{n_{p}}}}\right)
$$

The effective viscosity, $\nu_{e f f}$, is computed assuming that the total strain rate is the sum of brittle and ductile strain rates: $\nu_{\text {eff }}=1 /\left(\nu_{d}^{-1}+\nu_{b}^{-1}\right)$. The crust is supposed to be much weaker than mantle both in the brittle and ductile realms, to promote strain localization within the interplate crustal layer (Fig. 2). The low crustal friction coefficient $\left(\gamma_{c}=0.05\right)$ belongs to the classical range used to simulate realistic subduction dynamics (e.g., Tackley, 2000; Bird, 2003; Gerya et al., 2008; van Heck and Tackley, 2008). Other constants and parameters are listed in Table 2.

\subsection{Numerical resolution and investigated parameters}

The influence of mesh refinement is investigated by testing three numerical meshes, with an increasing refinement of the smallest mesh. The refined domain is limited to the rectangular area that encompasses the subduction plane and the mantle wedge tip (Table 1) where gradients of temperature, strain and stress are maximum. For the lowest resolution ("LR"), minimum node spacings are 2.85 and $2.27 \mathrm{~km}$ in the horizontal $(x)$ - and vertical $(z)$-directions. Both are decreased to $1.26 \mathrm{~km}$ in the most refined mesh ("HR"). A third mesh of intermediate resolution (labelled "MHR") is also tested. In all cases, the tracer density, uniform all over the simulation box, respects a minimum number of 7 markers in the smallest cell, which offers a sufficient accuracy in resolving the lithological difference (Arcay et al., 2005). Therefore, the total number of tracers increases from $1.2544 \times 10^{6}$ for grid LR to $5.76 \times 10^{6}$ for grid HR. 
The numerical mesh refinement will be first investigated. The influence of the subducting crust properties is tested nex. As mantle characteristics are fixed, I focus on the offset in activation energy between crust and mantle, $\Delta E_{a}$ : $\Delta E_{a}=E_{a}^{m}-E_{a}^{c}$, mantle being always stiffer than crust. The impact of $\Delta E_{a}$ on the down-dip extent of the subduction channel will be explored in details for two end-member ages at the trench of the subducting lithosphere (20 Myr and $100 \mathrm{Myr})$. All other parameters in equation 1 are kept identical. The density difference between crust $\left(\rho_{c}\right)$ and mantle $\left(\rho_{m}\right), \Delta \rho_{c}\left(=\rho_{c}-\rho_{m}\right)$, will be tested only for a young (20 Myr old) subducting plate, only moderately negatively buoyant. I will show how the pair $\left(\Delta E_{a}, \Delta \rho_{c}\right)$ modify the regime of young plate subduction. As a thick $(100 \mathrm{~km})$ upper plate is an usual feature of subduction zones but also an unfavorable condition for subduction initiation, it is imposed in all simulations.

\subsection{Estimate of the interplate down-dip extent}

The down-dip extent of the subduction channel may be considered either as a maximum depth of kinematic decoupling (Furukawa, 1993; Arcay et al., 2007b; Wada et al., 2008; Wada and Wang, 2009; Arcay, 2012), or as a minimum depth of viscous and kinematic coupling between subducting slab and asthenosphere. Since partial kinematic coupling might occur at depth shallower than the asthenosphere (e.g., Wada et al., 2008; Syracuse et al., 2010; van Keken et al., 2011, Fig. 1), it is more convenient to tag the subduction channel down-dip extent as a depth of significant slab-asthenosphere coupling, $z_{\text {coup }}$. To estimate $z_{\text {coup }}$, let us zoom in the interplate structure. At convergence start, as the incipient subducting slab enters the asthenosphere, the corner flow is directed towards the mantle wedge tip before turning downwards, dragged by the subducting slab (Fig. 3a, 2.35 Myr). The following cooling of the incoming plate rises thermal gradients at the mantle wedge tip, which enhances the corner flow and slightly shallows $z_{\text {coup }}$ (Fig. 3a, 4.4 Myr). The thermal structure and its associated $z_{\text {coup }}$ are stable (Fig. 3a, 25.3 Myr). Along the subduction channel, stress $(\tau)$ and strain $(\dot{\varepsilon})$, and thence rate of energy dissipation $(\tau \times \dot{\varepsilon})$, are very high up to the location where high strain rate jumps into the asthenosphere, where viscosity is low (Fig. 3d). The interplate geometry can hence be tracked by a $x-z$ profile joining maximum dissipation rates modelled at depth shallower than $\sim 120 \mathrm{~km}$ (Arcay, 2012). Along this profile, the average strain rate, $\dot{\varepsilon}$, is close to $2.6 \times 10^{-13} \mathrm{~s}^{-1}$ (Fig. 3d1), i.e., $\sim v_{c} / h_{c}$, where $v_{c}$ is convergence velocity $(6.5 \mathrm{~cm} / \mathrm{yr})$ and $h_{c}$ is the weak layer thickness. The interplate geotherm increases roughly linearly with depth until a high temperature increase that marks the proximity to asthenosphere (Fig. $3 \mathrm{~d} 2$ ). Therefore, $z_{\text {coup }}$ is defined by the depth along the interplate profile where a maximum thermal gradient and a strong strain rate decrease occur. Note that the distribution of high deformation rates, here obtained with a free slip-non deforming top surface and a weak crustal layer, reproduces well the strain rate pattern obtained in convection models including a free surface and a weak crust that simulate self-consistent singled-sided subduction (Schmeling et al., 2008)(Quinquis et al., 
2011; Crameri and Tackley, 2015).

\section{Influence of the numerical mesh}

A preliminary set of experiments with a $\sim 100 \mathrm{Myr}$ old, $\sim 100 \mathrm{~km}$ thick subducting lithosphere is performed to study how the numerical resolution affects the maximum interplate decoupling depth, $z_{\text {coup }}$ (simulations S1-10a to d, Table 3 ). The physical properties of the crust are kept constant. Using a coarse mesh (labelled LR, $x$ - and $z$-spacings of 2.8 and $2.3 \mathrm{~km}$, Table 1) yields a shallow $z_{\text {coup }}$, that stabilizes at the location where the crust content at computational nodes is lower than $99.9 \%$. To understand this result, note that the weak layer slightly thins, probably as a result of slab bending and/or internal shearing. Consequently, the weak layer is discretized by less than 4 nodes by the Eulerian mesh at $\sim 80 \mathrm{~km}$ depth (Figure $4 \mathrm{a}$, top). Close to the crust surface the average crust content at nodes drops from $100 \%$ to less than $99.1 \%$. A "contamination" by mantle tracers lower than $1 \%$ is sufficient to notably increase the strength averaged at nodes, which triggers the strain rate jump towards asthenosphere at low depth $(80 \mathrm{~km}$, Figure $4 \mathrm{a}$, top). With a more refined mesh (HRlim, $x-$ and $z$-spacings of $1.26 \mathrm{~km}$ ), the weak crust is discretized by more than 4 Eulerian nodes, among which 3 nodes at least display crust contents close to $100 \%$ : this enables the computation of an effective low strength at "crustal" nodes and deepens $z_{\text {coup }}$ to the level where the Eulerian mesh is not refined anymore (102 km depth, Figure 4a, bottom). By increasing the downwards extent of the refined area, $z_{\text {coup }}$ becomes independent of the numerical mesh $(114 \mathrm{~km}$, Figure $4 \mathrm{~b}$ ). A minimum number of 3 nodes to discretise the weak layer core, where crust content equals $100 \%$, appears to be the condition to simulate a mesh-independent coupling depth, as also observed by Crameri et al. (2012).

Refining the mesh increases node number but also the number of compositional tracers, to respect a minimum of 7 particles in the smallest mesh (tracer number multipleed by $\sim 5$, Table 1 ). The increase in node number and tracer density between grids LR and HR considerably rises computation time. To find a balance between discretization quality and computation time, a third numerical mesh is tested, with intermediate node spacings in the subduction plane area (MHR mesh, node spacing of $\sim 1.7 \mathrm{~km}$ ). To improve crust discretization, the crustal layer is also slightly thickened (from 6.9 to $8.3 \mathrm{~km}$, Table 1, Figure 4c). The $z_{\text {coup }}$ depth obtained with mesh MHR $(109 \mathrm{~km})$ is not exactly the one simulated with mesh HR $(114 \mathrm{~km})$. However, $\sim 85 \%$ of the difference between high and low resolution meshes is accounted for with the intermediate mesh, while mesh MHR allows for saving noticeably computation time. Mesh MHR is used in all simulations presented in the following. Numerical accuracy will be further discussed in section 6.1 . 


\section{Modelling results}

\subsection{Case 1: Subduction of a cold lithosphere}

In simulations S1-2 to S6-15 (Table 3), only the offset in activation energy between crust and mantle, $\Delta E_{a}$, is varied, from 20 to $155 \mathrm{~kJ} / \mathrm{mol}\left(E_{a}^{c}\right.$ varying from 445 to $310 \mathrm{~kJ} / \mathrm{mol}$ ). This large range of crust viscous strength enables to test different hypotheses on the lithology forming the subduction channel (sediments, basalt, gabbro, mantle, altered/hydrated phases, composite material). The lowest activation energy $\left(310 \mathrm{~kJ} / \mathrm{mol}, \Delta E_{a}=155 \mathrm{~kJ} / \mathrm{mol}\right)$ mimics a ductile strength encompassed between the ones of a dry quartzite (Ranalli and Murphy, 1987) and of a wet diorite (Ranalli, 1995, Fig. 5a). The strongest rheology $\left(E_{a}^{c}=445 \mathrm{~kJ} / \mathrm{mol}, \Delta E_{a}=20 \mathrm{~kJ} / \mathrm{mol}\right)$ simulates the strength of a dry mafic granulite (Wilks and Carter, 1990).

\subsubsection{Influence of interplate strength on the corner flow structure}

Softening the interplate channel (increasing $\Delta E_{a}$ ) increases $z_{\text {coup }}$ (Figure $5 \mathrm{~b})$. The largest $z_{\text {coup }}, 163 \mathrm{~km}$ depth, is modelled for $\Delta E_{a}=135 \mathrm{~kJ} / \mathrm{mol}$. Conversely, the stiffest subducting crust $\left(\Delta E_{a}=20 \mathrm{~kJ} / \mathrm{mol}\right)$ shallows $z_{\text {coup }}$ to $60 \mathrm{~km}$ depth. This $\Delta E_{a}-z_{\text {coup }}$ trend was already observed by Wada et al. (2008) and described in Arcay (2012), but the values of $z_{\text {coup }}$ obtained here are significantly different thanks to the improved resolution. Surprisingly, for the weakest crust $\left(\Delta E_{a}=155 \mathrm{~kJ} / \mathrm{mol}\right)$, the jump of localized strain from the interplate to the asthenosphere does not occur in the numerically refined domain (Fig. 6a2): The crust is so weak that it remains softer than the asthenosphere, which maintains strain localization within the subducting crust. $z_{\text {coup }}$ is shifted at the boundary between fine and coarse meshes, at $250 \mathrm{~km}$ depth. As the warm corner flow is offset downwards, the fore-arc lithosphere significantly thickens by cooling. The major part of the cold mantle wedge is motionless. For $135<\Delta E_{a}<155$ $\mathrm{kJ} / \mathrm{mol}$, an in-between behaviour is modelled. Near the base of the overriding plate $(\sim 100 \mathrm{~km}$ depth$)$, convergence is partly transmitted to the fore-arc base (velocities $<0.5 \mathrm{~cm} / \mathrm{yr}$, Fig. 6a1). I label $z_{\text {partial-coup }}$ the shallowest depth along the subduction channel where partial kinematic coupling is modelled (Fig. 6a1). It equals $110 \pm 10 \mathrm{~km}$ in simulation S1-14 $\left(\Delta E_{a}=145 \mathrm{~kJ} / \mathrm{mol}\right)$. Partial kinematic coupling between slab and asthenosphere progressively increases downwards. $z_{\text {coup }}$ is defined instead by the coupling depth where rocks overlying the downgoing plate are asthenospheric (hot temperature) and are dragged with velocities close to subduction speed $(>3 \mathrm{~cm} / \mathrm{yr})$. According to this definition, $z_{\text {coup }}$ for $\Delta E_{a}=145 \mathrm{~kJ} / \mathrm{mol}$ varies through time but globally deepens, up to $200 \mathrm{~km}$ depth (Figure $5 \mathrm{~b}$ ). The $z_{\text {coup }}$ dependence on time is likely to be a numerical effect, related to transient thinnings of the weak layer that would possibly disappear by increasing resolution. Nonetheless, the layer of partial kinematic decoupling forms on the whole at the upper plate-asthenosphere boundary, independently of numerical resolution. Note that the $\Delta E_{a}$ range resulting in partial kinematic coupling is quite narrow $\left(135<\Delta E_{a}<155 \mathrm{~kJ} / \mathrm{mol}\right)$. For a bit younger subducting plate $\left(A_{t}=60 \mathrm{Myr}\right.$, simulations S6-2 to S6-15), the dependence of the interplate structure on crust strength is similar to the 
one simulated for a $100 \mathrm{Myr}$ old lithosphere (Figure 5b). The main differences are subduction failure if the oceanic crust is too resistant $\left(\Delta E_{a}=20 \mathrm{~kJ} / \mathrm{mol}\right)$ and a general slight $z_{\text {coup }}$ deepening compared to $A_{t}=100 \mathrm{Myr}$. The striking cooling of the fore-arc lithosphere is modelled when $\Delta E_{a} \geq 145 \mathrm{~kJ} / \mathrm{mol}$, and partial kinematic coupling occurs at the base of the fore-arc since $\Delta E_{a}=135$ $\mathrm{kJ} / \mathrm{mol}$ (Figure $5 \mathrm{~b}$ ). The numerically-induced variations in $z_{\text {coup }}$ are however much wider than simulated when $A_{t}=100 \mathrm{Myr}$.

To summarise, the fore-arc base heating or cooling depends on the corner flow structure, which depends on $\Delta E_{a}$. The downwelling stream of the corner flow is well developed whatever crust strength, since the asthenosphere sticking to the slab ("viscous blanket", Kincaid and Sacks, 1997, Fig. 3b) does not depend on $\Delta E_{a}$. On the contrary, the horizontal part of the corner flow is fast and focussed at the upper plate base only if $\Delta E_{a}$ is rather low $(<135 \mathrm{~kJ} / \mathrm{mol}$, Fig. $3 a)$, and provides in this case a significant advected heat at the fore-arc base that thins it. The horizontal mantle flow gets more and more diffuse as $\Delta E_{a}$ is risen, which restrains fore-arc basal heating (compare Fig. 6a to Fig. 3a). When $\Delta E_{a}=155 \mathrm{~kJ} / \mathrm{mol}$, the heat advected towards mantle wedge tip is so reduced that the fore-arc conductive cooling is unbalanced.

\subsubsection{Effect of a very weak subduction channel on partial melting in the mantle wedge}

To explore the consequences of an extreme cooling of the fore-arc lithosphere when $\Delta E_{a} \geq 145 \mathrm{~kJ} / \mathrm{mol}$, water transfers associated with slab dehydration and overlying rock hydration are computed in simulations S1-14 and S1-15 (Fig. 6a3). The subducting oceanic crust and the underlying layer of serpentinised mantle ( $7 \mathrm{~km}$ thick) are both assumed to be water-saturated before subduction (containing respectively 2.93 and $6.5 \%$ in weight of water). Phase transitions controlling water transfers are predicted by using pressure-temperature paths of lithological tracers, based on accurate phase diagrams determined for a water-saturated peridotite (Schmidt and Poli, 1998) and a gabbroic composition (Bousquet et al., 1997). The model of water expelling, upwards migration, and absorption by the nearest under-saturated marker above the dehydrating element, extensively described and tested in previous papers (Arcay et al., 2005, 2006, 2007b,a, 2008) will not be detailed here. Water transfers are passive and do not affect mantle and crust properties. The key result of the experiment S1-15 is that the mantle wedge hydrated by slab dehydration is too cold to allow for the triggering of mantle melting in wet conditions. Let us assume that the lowest temperature of wet mantle solidus is $980^{\circ} \mathrm{C}$ (Green, 1973; Millholen et al., 1974; Schmidt and Poli, 1998). The progressive cooling of the fore-arc lithosphere shifts away from the trench this critical isotherm (Fig. 6a3): at times longer than 16.4 Myr, all the water released by slab dehydration saturates a mantle wedge whose temperature is well below $980^{\circ} \mathrm{C}$, as above one slab dehydration front a column of chlorite forms $\left(T \lesssim 850^{\circ} \mathrm{C}\right.$, water content of 2.1 \%wt, Fig. 6a3, inset). Consequently, the model predicts that the volcanic arc activity of the subduction zone should stop despite a significant fluid flow ex- 
pelled from the slab, which is the eventual outcome of a very weak subduction channel. Regarding anhydrous mantle melting, it is all the more impeded as it required temperature hotter than wet partial melting. When $\Delta E_{a}=145 \mathrm{~kJ} / \mathrm{mol}$ (simulation S1-14), the fore-arc cooling is not as excessive as in the preceeding case: Partial melting within the hydrated mantle wedge is allowed in a limited hot region. For $A_{t}=60 \mathrm{Myr}$ (simulation S6-13), partial kinematic coupling enhances fore-arc cooling through time. The mantle located ontop of the slab dehydration front the farthest from the trench (chlorite out) is predicted to be too cold to enable mantle melting $\left(T \leq 980^{\circ} \mathrm{C}\right)$ when convergence duration exceeds 20 Myr. The use of the wet solidus determined by Green (1973) and Millholen et al. (1974) to assess mantle melting occurence in water-saturated condition will be discussed in section 6 .

\subsection{Case 2: Subduction of a young and warm lithosphere}

In this section, experiments simulate the subduction of a young incoming lithosphere, $\sim 40 \mathrm{~km}$ thick and aged of $20 \mathrm{Myr}$ at trench. For a hot downgoing plate, the efficiency of mechanical decoupling across the subduction interface may be a function not only of the subduction channel strength $\left(\Delta E_{a}\right)$ but also of the weak layer density $\left(\Delta \rho_{c}\right)$. Indeed, the total slab weight favouring subduction is more sensitive to crust density than in the case of a cold incoming plate, whose mantle density is high and lower the relative effect of crust density. The range of investigated $\Delta E_{a}$ is enlarged to $220 \mathrm{~kJ} / \mathrm{mol}\left(E_{a}^{c}=245 \mathrm{~kJ} / \mathrm{mol}\right)$, that simulates the weak strength of a granite (Mackwell et al., 1998, Fig. 5a). The density of the oceanic crust varies between $2920 \mathrm{~kg} \cdot \mathrm{m}^{-3}\left(\Delta \rho_{c}=-380 \mathrm{~kg} \cdot \mathrm{m}^{-3}\right)$, which is close to the density of gabbro $\left(2940 \mathrm{~kg} \cdot \mathrm{m}^{-3}\right)$ or andesite $\left(2900 \mathrm{~kg} \cdot \mathrm{m}^{-3}\right)$ in the greenschist facies (Bousquet et al., 1997), and $3550 \mathrm{~kg} \cdot \mathrm{m}^{-3}\left(\Delta \rho_{c}=+250\right.$ kg. $\mathrm{m}^{-3}$ ), corresponding to the density of an eclogitized gabbro (Bousquet et al., 1997). The mantle density is kept constant (3300 kg.m ${ }^{-3}$ at the surface).

\subsubsection{Subduction regime as a funtion of $\Delta E_{a}$ and $\Delta \rho_{c}$}

Figure 7 sums up the broad variety of subduction patterns modelled for $A_{t}=20$ Myr depending on the pair $\left(\Delta E_{a}, \Delta \rho_{c}\right)$ (simulations S2-2a to S2-22g, Table 3). Different behaviours may be modelled simultaneously, yielding overlappings domains. Domain 1 may be defined where subduction aborts rapidly $(<10 \mathrm{Myr})$ : the subduction plane is blocked and convergence localises ahead of the trench (white domain in Fig. 7, inset 1). For a stiff crust $\left(\Delta E_{a} \leq 40\right.$ $\mathrm{kJ} / \mathrm{mol})$, subduction is possible only if crust is denser than the mantle $\left(\Delta \rho_{c}>0\right)$. The softer the crust is, the wider the range of crust density allowing subduction is (yellow domain). However, near the outline of the subduction domain, stresses within the upper plate are highly compressive (light brown domain in Fig. 7, inset 4): subduction would probably stop if convergence was driven by a constant force less than $10^{13} \mathrm{~N} / \mathrm{m}$ (computed as explained in section 3.1) instead of constant velocity. When the crust is denser than the mantle, early slab breakoff occurs if crust is too stiff, followed by subduction obstruction $\left(\Delta E_{a} \leqslant 40\right.$ $\mathrm{kJ} / \mathrm{mol}$, left green domain, inset 6). At slightly higher $\Delta E_{a}$ and positive $\Delta \rho_{c}$, 
the incipient subduction zone is unstable, and the slab finally detachs from the surface (purple domain, inset 7). On the contrary, for a weak and dense crust, the early slab break-off does not repeat and subduction is stable $\left(\Delta E_{a} \geqslant 105\right.$ $\mathrm{kJ} / \mathrm{mol}$, right green domain, inset 5). The initial slab drip could be related to the weakness of the incipient plate (Andrews and Billen, 2009), and/or to the low activation volume (Crameri et al., 2012).

When the crust is weak and buoyant, small crust plumes initiate near the upper lithosphere-asthenosphere boundary $(\sim 110 \pm 15 \mathrm{~km}$ depth, if the crustal geotherm at this depth is hot enough $\left(T \sim 1000^{\circ} \mathrm{C}\right.$, Fig. $6 \mathrm{~b} 2$; red domain in Fig. 7 inset 2). Two levels of crust plume formation are modelled in a few simulations, the deeper one occuring at $\sim 130 \mathrm{~km}$ depth (section 5.2.2). Crust plumes have been modeled by Vogt et al. (2013) and Maunder et al. (2016) in the same depth range for similar densities and rheological parameters, but for a much thinner upper plate $(\sim 50 \mathrm{~km})$ and for slower convergence. In the present study, crust diapirism may be promoted by shear heating in the subduction channel. In the Archean, the underplating of crust plumes along the overlapping plate Moho ("relamination") has been suggested to explain the lower continental crust differentiation, as crust plumes may include partially molten crust (Hacker et al., 2011). Crust plumes do not form for an extremely weak and buoyant crust $\left(\Delta E_{a}=220 \mathrm{~kJ} / \mathrm{mol}\right.$ and $\Delta \rho_{c}=-380 \mathrm{~kg} \cdot \mathrm{m}^{-3}$, simulation S2-22a). The subducting crust thickens the subduction channel by accumulating at depth shallower than $\sim 100 \mathrm{~km}$ and locally convect (velocity of $\sim 5 \mathrm{~cm} / \mathrm{yr}$, blue domain in Fig. 7, inset 3). The subduction plane thickening, modeled by Maunder et al. (2016) for a similar crustal rheology, was deemed to be a plate tectonics regime in the Archean (Hoffman and Ranalli, 1988).

\subsubsection{Partial kinematic coupling and thermal state of the fore-arc lithosphere}

As the formation of crustal plumes triggers partial kinematic coupling at the extremity of the subduction channel, the experiments showing crustal diapirism are detailed in this section, illustrated by simulation S2-17b. When instabilities of buoyant crust initiate at $\sim 100 \mathrm{~km}$ depth, $z_{\text {coup }}$ is shifted to $137 \mathrm{~km}$ depth while partial kinematic coupling occurs between the plume root and $z_{\text {coup }}$ (Fig. $8 \mathrm{a}, 9 \mathrm{Myr})$. Soon a secondary branch of asthenospheric corner flow forms reaching the root of the main crust plume ( $\sim 90 \mathrm{~km}$ depth, $14.2 \mathrm{Myr})$. This rises $z_{\text {coup }}$ to $z_{\text {partial-coup }}$, leading to a classical velocity field with a fast corner flow ( $>3$ $\mathrm{cm} / \mathrm{yr}$, Fig. 8a, $15.2 \mathrm{Myr}$ ), before $z_{\text {coup }}$ deepens again to $\sim 190 \mathrm{~km}$ at $18.9 \mathrm{Myr}$. The crust flow within the main plume (clock-wise current) cools the fore-arc. The crust spinning sense is reversed when $z_{\text {coup }}$ rises up to the crust plume head, resulting in a fore-arc warming (Fig. 8, 14.2 Myr). The sequence of forearc cooling induced by crust upwelling, followed by a fast warming related to asthenospheric rising, occurs repeatedly. Crust instability thus basically entails (1) a high time-dependence of the fore-arc structure, and (2) an intermittent but intense cooling of the fore-arc domain.

Outside the domain of crust instability, partial kinematic coupling appears when crust buoyancy exceeds $-140 \mathrm{~kg} \cdot \mathrm{m}^{-3}$ at $\sim 114 \mathrm{~km}$ depth. Figure $8 \mathrm{~b}$ depicts the 
typical evolution simulated in simulation S2-13g: $z_{\text {coup }}$ deepens with time (from $175 \mathrm{~km}$ to $\sim 200 \mathrm{~km}$ depth between 8.1 and $10.2 \mathrm{Myr}$ ), before being suddenly shallowed when the asthenosphere rises up to $z_{\text {partial-coup }}(113 \mathrm{~km}, 12,8 \mathrm{Myr})$. The $z_{\text {coup }}$ deepening followed by quick shallowing is once again a repeating process (Fig. 8).

\subsection{3. $z_{\text {coup }}$ dependence on $\Delta E_{a}, \Delta \rho_{c}$, and time}

Figure 9 displays $z_{\text {coup }}$ variations with crust strength and buoyancy after $\sim 10 \mathrm{Myr}$ of convergence (panel a). $z_{\text {coup }}$ is mainly constant through time in the absence of crust plume, but becomes strongly time-dependent otherwise. The transient state resulting from fast $z_{\text {coup }}$ shallowings up to the depth of $z_{\text {partial-coup }}$ is captured in panel $\mathrm{b}$, where the shallowest $z_{\text {coup }}$ value simulated between 10 and $13.5 \mathrm{Myr}$ of convergence is mapped. First, the large range of $z_{\text {coup }}$ modelled for $A_{t}=20 \mathrm{Myr}$ varies from $50 \mathrm{~km}$ to $250 \mathrm{~km}$ depth. This maximum depth modelled at $13.5 \mathrm{Myr}$ in simulation $\mathrm{S} 2-17 \mathrm{c}\left(\Delta E_{a}=175 \mathrm{~kJ} / \mathrm{mol}\right.$; $\left.\Delta \rho_{c}=-240 \mathrm{~kg} \cdot \mathrm{m}^{-3}\right)$ is controlled by the mesh coarsening. Second, in the domain where $z_{\text {coup }}$ is stable (for $\Delta \rho_{c} \gtrsim-120 \mathrm{~kg} . \mathrm{m}^{-3}$ ), the coupling depth deepens when $\Delta E_{a}$ increases, as already described for $A_{t}=100 \mathrm{Myr}$ (section 5.1.1). At constant crust strength, $z_{\text {coup }}$ slightly deepens with increasing crust buoyancy, possibly because of a decrease in slab dip angle (compare modelled slab dips in insets 2, 4 and 5 in Figure 7), though the relationship between slab dip angle and crust buoyancy may not be so straightforward (compare insets 5 and 3). Third, when $z_{\text {coup }}$ is time-dependent, crust plumes and partial kinematic coupling strongly increase $z_{\text {coup }}(>150 \mathrm{~km})$, this deepening being partly counterbalanced by punctual upwards $z_{\text {coup }}$ jumps that temporarily reverse the $z_{\text {coup }}-\Delta E_{a}$ trend observed for $\Delta \rho_{c}>-120 \mathrm{~kg} \cdot \mathrm{m}^{-3}$ (solid black squares in Fig. $9 \mathrm{~b})$.

\subsubsection{Wet mantle melting as a function of $z_{\text {coup }}$ evolution}

Water transfers are computed in 10 experiments of young plate subduction to evaluate the likelihood of wet mantle melting (purple symbols in Fig. 9a). As mantle melting is not directly computed, I focus on the water flux that should trigger melting. To trigger melting at the slab surface, the water flux expelled by slab dehydration must be not only significant but also absorbed at temperature hotter than $980^{\circ} \mathrm{C}$ (lowest wet solidus for peridotite, section 5.1.2). In the present modelling this water is first dissolved in the asthenosphere and fore-arc base (water content at saturation $<0.05 \mathrm{wt} \%$, Arcay et al., 2005). If there is some left, the remaining water hydrates the cold overlapping lithosphere where nominally hydrated phases form (amphibole, talc, serpentine), increasing water contents above $0.5 \mathrm{wt} \%$. Water contents in the upper plate, that here acts as a "sponge", are thus tracked to estimate the water amount available at slab surface at $T>980^{\circ} \mathrm{C}$ that would normally yield mantle melting (Fig. 10). Three melting regimes are modelled. If fore-arc cooling is limited $\left(z_{\text {coup }} \lesssim 140 \mathrm{~km}\right)$, one part of dehydration water should always be absorbed at $T>980^{\circ} \mathrm{C}$ in amounts greater than $0.5 \mathrm{wt} \%$, which might be sufficient for sustaining the volcanic front 
activity even if the corresponding metasomatized domain is narrow (Fig. 10a, solid triangles in Fig. 9). If fore-arc cooling is intense $\left(z_{\text {coup }}\right.$ always $\left.\geq 160 \mathrm{~km}\right)$, almost all the released water is absorbed at temperature below wet solidus (Fig. 10c, crosses in Fig. 9). Therefore, the volcanic front activity would probably vanish. An intermediate regime occurs if mantle wedge cooling is disturbed by sudden $z_{\text {coup }}$ shallowings. Compared to the previous situation, transient forearc warmings extend mantle melting for a while (Fig. 10b, empty triangles in Fig. 9). Magma supply and volcanic front activity might be intermittent in this case. In conclusion, the mantle wedge cooling resulting from the subduction channel weakness significantly restricts wet mantle melting for $A_{t}=20 \mathrm{Myr}$, as already described for older plate subduction.

\subsection{Synthesis}

5.3.1. Decoupling along the subduction interface as a function of slab age, crust buoyancy, and interplate rheology

Figure 11 schematizes how crust strength and slab weight regulate kinematic decoupling between converging plates in this modelling. As already mentioned, the weight of the downgoing slab depends here on crust density and on lithosphere age at trench (Turcotte and Schubert, 1982). If $A_{t} \geq 60 \mathrm{Myr}$, the average slab density exceeds the asthenospheric one whatever crust buoyancy. The resulting slab weight excess promotes high dip angle $\left(>30^{\circ}\right)$ when the incipient slab enters the asthenosphere. This activates the corner flow that eases kinematic decoupling at the interplate down-dip extent and, finally, subduction. This process is only slightly sensitive to the subduction channel strength (purple domain in Fig. 11). Nonetheless, the latter controls the structure of the horizontal branch of the corner flow: fast, focussed and warming the fore-arc base when $\Delta E_{a}$ is low (red area in Fig. 12), and inversely slow, diffuse and advecting a low heat flux at the mantle wedge tip when $\Delta E_{a}$ is high (blue area). On the contrary, if $A_{t}=20 \mathrm{Myr}$, as mantle slab density is minimum, crust buoyancy has a significant influence on the total slab weight excess. If $\Delta \rho_{c}=-380 \mathrm{~kg} \cdot \mathrm{m}^{-3}$, the low dip angle of the incipient slab hampers corner flow activation. Subduction initiates only if the interplate decoupling is very efficient up to asthenospheric levels, i.e., if crust is quite weak (yellow domain in Fig. 11). If the subducted crust is not so buoyant $\left(\Delta \rho_{c} \geq 0\right)$, the increase in slab dip angle helps the corner flow triggering and lowers the minimum $\Delta E_{a}$ enabling subduction.

\subsubsection{Fore-arc structure as a function of subducting plate age and crust weak- ness}

Figure 12 sums up the major characteristics of the fore-arc structure modelled as a function of incoming plate age, $A_{t}$, and crust weakness, $\Delta E_{a}$, for a crust buoyancy set to $-380 \mathrm{~kg} \cdot \mathrm{m}^{-3}$. To begin with, along the boundary delimiting subduction, the depth of slab-asthenosphere coupling is the shallowest that can be modelled for a given $A_{t}$, since $\Delta E_{a}$ is the lowest (Fig. 5b). Therefore, the fore-arc lithosphere base is predicted to be there the warmest (red area). 
This is nonetheless not true for a $20 \mathrm{Myr}$ old incoming lithosphere subducting only for very weak crust, which leads to fore-arc cooling and cold crust diapirism (green area). Fore-arc cooling by $z_{\text {coup }}$ deepening occurs if $\Delta E_{a} \geq 155 \mathrm{~kJ} / \mathrm{mol}$ whatever subducting plate age, and can be intense enough to prevent mantle melting in wet conditions (blue area). Lastly, partial kinematic coupling at fore-arc base is modelled in a narrow range of crust strength $\left(135<\Delta E_{a}<155\right.$ $\mathrm{kJ} / \mathrm{mol}$ if $A_{t}=100 \mathrm{Myr}$ ), and moderately cools the fore-arc. The depth where partial kinematic coupling starts, $z_{\text {partial-coup }}$, is mainly a function of the upper plate thickness. As partial kinematic coupling is systematically associated with Rayleigh-Taylor crustal instabilities when $A_{t}=20 \mathrm{Myr}$, the domain of partial kinematic coupling for $A_{t} \leq 60 \mathrm{Myr}$ is assumed to merge with the domain of cold crust plumes. To conclude, no universal subduction plane strength is able to simulate alone realistic subduction, whatever subducting plate age, if the crust is significantly buoyant and the overlapping plate thick $(\sim 100 \mathrm{~km})$.

\section{Discussion and concluding remarks}

\subsection{Study limitations}

Two main shortcomings can be underlined: (1) the numerical scheme used to interpolate strength from lithological markers'properties, and (2) modelling the subduction channel by a rheological contrast constant with depth. The viscosity at Eulerian nodes can be computed from markers' values (1) using an arithmetic averaging, assuming deformation at constant strain rate (such as pure shear parallel to compositional layering, Schmeling et al., 2008). On the contrary, a harmonic averaging simulates simple shear (at constant stress) parallel to the channel surface. While arithmetic averaging yields a numerical strengthening, the harmonic one reproduces well a thin channel low viscosity, and is more adapted to simulate a subduction channel (Schmeling et al., 2008; Deubelbeiss and Kaus, 2008). As both kinds of shear are expected in a subducting slab, the averaging scheme should change depending on deformation pattern, which is not easy to handle numerically (Schmeling et al., 2008). Geometric averaging leads to a in-between averaged strength. In the present study, brittle and ductile rheologies are combined through harmonic averaging (section 3.2) while viscosity at nodes is estimated from compositional markers by an arithmetic averaging. The subduction channel strengthening simulated for a coarse mesh (section 4) directly results from arithmetic averaging. To better model viscosity layering associated with lithological boundaries, resolution may be improved by either (i) increasing the number of Eulerian nodes or thickening the low viscosity layer when arithmetic averaging is used (as in this study), (ii) decreasing the interpolation volume around Eulerian nodes (Duretz et al., 2011), (iii) limiting irregularities in marker distribution by implementing a conservative velocity interpolation scheme (Wang et al., 2015), or (iv) modeling compositional interface during marker advection, through for instance the particle level set method (Samuel and Evonuk, 2010). 
Imposing a ductile strength contrast $\Delta E_{a}$ constant with depth along the subduction channel (2) supposes that lithological variations are small. It is more likely that the medium composing the interplate changes with depth, from, possibly, sediments at shallow depth, upper then lower crusts, to more mafic composition at great depth. This lithological sequence could be simply modelled by a strength increase along the subduction channel, i.e., by a $\Delta E_{a}$ decrease with depth (Fig. 5a). As low $\Delta E_{a}$ yields $z_{\text {coup }}$ shallowing (Fig. 5b and 9), a $\Delta E_{a}$ lowering with depth should shallow $z_{\text {coup }}$. If softening minerals locally form, such as serpentine at high depth (Duarte et al., 2015), a localized $\Delta E_{a}$ increase might favor $z_{\text {coup }}$ deepening, but this would have to remain limited, otherwise volcanic arc extinction by mantle wedge cooling might occur (Fig. 12).

\subsection{Partial kinematic coupling}

Partial kinematic coupling next to the mantle wedge tip would explain the extent of the "cold fore-arc nose" detected in seismic tomographies (e.g., Zhao et al., 1992; Zhao, 2001; Stachnik et al., 2004; Abers et al., 2006, Fig. 3). Partial kinematic coupling would result from ductile strain localized within weak materials, such as sediments or hydrated phases (serpentine, talc, Peacock and Hyndman, 1999), or brittle deformation occurring deeper than the brittle-ductile transition. In thermo-kinematic models, partial kinematic coupling is modelled by imposing a given percent of kinematic coupling over a specified length at the subduction plane extremity. Coupling abruptly passes from partial to full to mimic the effect of a dehydration reaction on viscous coupling (Kneller et al., 2005, 2007; Syracuse et al., 2010). A low coupling (2-3\%) between 40 and $70 \mathrm{~km}$ depth cools the fore-arc while sustaining a sharp sub-vertical boundary between low-temperature fore-arc and hot asthenospheric wedge, consistent with seismic cross-sections and heat flow profiles. An increased coupling ( $10 \%)$ leads to a cooling of the subduction plane down-dip extent while a "hot tongue" of asthenosphere rises up to the location where full decoupling between converging plates is imposed ( $\sim 40 \mathrm{~km}$ depth). This odd thermal structure is actually not consistent with seismic tomographies. The present study shows that partial kinematic coupling may form according to the incoming plate age and the subduction plane strength (135-145 kJ/mol if $A_{t}=100 \mathrm{Myr}$, enlarged to $\Delta E_{a}>$ $120 \mathrm{~kJ} / \mathrm{mol}$ if $A_{t}=20 \mathrm{Myr}$, Fig. 7). The transition to full kinematic coupling is then progressive (from 0 to $\sim 7 \%$ ) and occurs on a large distance $(>100 \mathrm{~km}$ extent), while it is pinpointed and thus very sharp in thermo-kinematic models. The thermal structure modelled at slab surface is then much more smoothed than in thermo-kinematic modellings.

\subsection{Diapirism-induced fore-arc cooling, numerical resolution, and mantle melt- ing prediction}

In this modelling, $z_{\text {coup }}$ is mesh-independent if the weak layer core is discretized by more than 3 computational nodes. Otherwise, the artificial strengthening of the subduction channel triggers a hot mantle upwelling to soften the interplate, ending in a numerical shallowing of $z_{\text {coup }}$. When crust plumes are 
modelled, they reduce the crustal channel thickness. As a consequence, the asthenospheric corner flow frequently rises up to the root of crust instabilities. The sporadic upwards jumps of $z_{\text {coup }}$ are thus probably a numerical effect that could be limited using a more refined mesh. The thermal state of the fore-arc would then be even colder and wet mantle melting even more hindered than simulated for $A_{t}=20 \mathrm{Myr}$. This is consistent with the general fore-arc cooling modelled for older incoming plates at high crust strength reduction.

\subsection{Can nominally hydrated phases be stable at the slab surface?}

Two main layers of hydrous phases are assumed to release the water responsible for partial melting in the mantle wedge. The deeper one is located within the subducting slab, inside the oceanic crust and/or the underlying serpentinized mantle. The second one would be the viscous blanket covering the downgoing slab (Fig. 3b), hydrated by the underlying dehydrating layers. Amphibole and serpentine have been assumed to be stable at the slab surface (Iwamori et al., 2007; Wada et al., 2008; Hirauchi and Katayama, 2013), but chlorite would the hydrated phase stable at the hottest temperature at high depth $\left(\sim 860^{\circ} \mathrm{C}\right.$ at 60-100 km depth, Schmidt and Poli, 1998; Grove et al., 2004, 2009; Till et al., 2012). Chlorite destabilization would provide the water triggering melting at the bottom of the mantle wedge (Till et al., 2012, see section 6.5). Still, chlorite stability was assessed based on thermal models performed with a temperaturedependent Newtonian viscosity. If the stress-dependence of olivine rheology is included, the increase in thermal gradient at the slab surface (van Keken et al., 2002; Syracuse et al., 2010) prevents the formation of stable chlorite. Similarly, the simulations performed in this study predict that chlorite cannot form at the base of the mantle wedge if $\Delta E_{a}<135 \mathrm{~kJ} / \mathrm{mol}$ (Fig. 13). Chlorite formation at high depth is predicted when the simulated subduction zones are the coldest, notably when $z_{\text {coup }}$ is extremely deep (> $160 \mathrm{~km}$ depth, Fig. $6 a 3$ and 10a,b). However, since hydrous minerals may be softening materials, their formation would lower the asthenosphere viscous drag at the slab surface, emphasizing wedge cooling and melting hindrance. Finally, as the crust mainly dehydrates before reaching the asthenosphere (Fig. 6a3), this study suggests that the deserpentinization of the subducting mantle may be the major source of the water triggering melting in the mantle wedge.

\subsection{Solidus assumed to assess wet mantle melting}

When the subduction channel is particularly weak $\left(\Delta E_{a} \geq 135 \mathrm{~kJ} / \mathrm{mol}\right.$, or a bit more depending on $\Delta \rho_{c}$ if $A_{t}=20 \mathrm{Myr}$ ), the water released by slab dehydration is predicted to be absorbed in the mantle wedge at temperature below the wet solidus, switching off the volcanic front activity. The model assumes the minimum temperature of the wet solidus to be $980^{\circ} \mathrm{C}$, as estimated by Kushiro et al. (1968) and Green et al. (2010). However, other experiments performed on longer durations (Mysen and Boettcher, 1975; Grove et al., 2004; Till et al., 2012), and/or based on peridotite samples less depleted in iron (Grove et al., 2012) suggest a lower wet mantle solidus, related to the chlorite stability field: 
$810 \pm 10^{\circ} \mathrm{C}$ between $\sim 2$ and $4 \mathrm{GPa}$. Therefore, the inhibition of mantle melting induced by an extreme $z_{\text {coup }}$ deepening might not occur if the relatively cold wet solidus of Till et al. (2012) was taken into account. Nonetheless, the strong fore-arc cooling (modelled for instance in simulation S1-15, Fig. 6a3) is artificially limited by the numerical mesh coarsening imposed at $250 \mathrm{~km}$ depth. The fore-arc would thus be even more cooled if mesh coarsening was shifted to the base of the simulation box. Finally, I assume that, at least on long-time scales (>30 Myr), the fore-arc conductive cooling would prevent mantle partial melting whatever the considered wet solidus.

\subsection{Slab surface temperature}

To discuss the range of realistic subduction channel strengths, let us consider the thermal state modelled along the subducting slab surface, defined as the top of the downgoing oceanic crust, for $A_{t}=100 \mathrm{Myr}$. (Fig 13d). Slab surface temperature (SST) are compared with pressure-temperature $(P-T)$ conditions estimated from geothermometry derived from $\mathrm{H}_{2} \mathrm{O} / \mathrm{Ce}$ measurements on melt inclusions (Plank et al., 2009; Cooper et al., 2012). Data are compiled from very different subduction zones, such as slow subduction of young plates (e.g., Cascadia) or fast subduction of old plates (NE Japan or Tonga). They cannot not be directly compared with modelled SST, but rather considered as upper and lower boundaries. Modelling an overlapping plate thinner than simulated would also probably shift SST to lower depth. The modelling subduction setup simulates the one prevailaing in the Kamchatka (Heuret and Lallemand, 2005). Imposing a stiff oceanic crust $\left(\Delta E_{a}=20 \mathrm{~kJ} / \mathrm{mol}\right.$, Fig 13a) yields a slab surface much hotter than observed, while the strong fore-arc cooling associated with a weak suduction channel $\left(\Delta E_{a} \geq 135 \mathrm{~kJ} / \mathrm{mol}\right.$ ) produces too cold SST (Fig $13 \mathrm{~b}$ and $\mathrm{d}$ ). Imposing $\Delta E_{a}=80 \mathrm{~kJ} / \mathrm{mol}$ reproduces the hotter observed SST, whereas SST obtained with $\Delta E_{a}=105 \mathrm{~kJ} / \mathrm{mol}$ correctly simulate the $P-T$ conditions observed in the Kamchatka. We should expect the modelled SST to be colder than estimated along several young and/or slow subducting plates (South Chile, Nicaragua or Lesser Antilles), but it is the inverse that is simulated. This would argue for increasing $\Delta E_{a}$ to $\sim 120 \mathrm{~kJ} / \mathrm{mol}$ to moderate SST increase. I conclude that the $\Delta E_{a}$ range that mimics best worldwide SST estimates from thermometry is $80-120 \mathrm{~kJ} / \mathrm{mol}$.

Moreover, the shallowest and hottest nose in the mantle wedge may be constrained by conditions of last equilibration with the mantle of near-primary arc magmas (Kelemen et al., 2003, Fig. 13a), considered as the signature of hydrated melts reaching the upper plate Moho. Still, hot conditions at the arc Moho may derive from the heat advected by melt migration, which is here neglected. The hottest mantle wedge is modelled for the stiffest subduction channel, but the hot nose is not as shallow as observed $\left(\Delta E_{a}=20 \mathrm{~kJ} / \mathrm{mol}\right.$, lines with stars in panel 13d). To reproduce observations, an additional ingredient must be included to enhance the corner flow. In simulation S1-8b, first, water transfers associated with slab dehydration/mantle wedge hydration are simulated (section 5.1.2); second, an hydrous strength reduction whose amplitude increases with water content $\left[\mathrm{OH}^{-}\right]$is imposed for the hydrated mantle: low 
reducing factor (increasing from 5 to 32 ) when water is dissolved in nominally anhydrous minerals $\left(200 \mathrm{ppm} \leq\left[\mathrm{OH}^{-}\right] \leq 0.2 \mathrm{wt} \%\right.$ ), high and maximum (set to 350 ) when hydrous minerals form (e.g., amphibole, $\left\lceil\mathrm{OH}^{-}\right\rceil \geq 0.5 \mathrm{wt} \%$, Arcay et al., 2005, Fig. 13c). $\Delta E_{a}$ is set to $80 \mathrm{~kJ} / \mathrm{mol}$. Viscosity is then low in the hydrated mantle wedge $\left(\sim 10^{18}\right.$ Pa.s at $\sim 50 \mathrm{~km}$ depth, Fig 13c), which shallows $z_{\text {coup }}$ to $\sim 48 \mathrm{~km}$ and simulates the shallow and hot mantle nose inferred from near-primary arc magmas $\left(1250^{\circ} \mathrm{C}\right.$ at $\sim 50 \mathrm{~km}$ depth, Fig. $\left.13 \mathrm{~d}\right)$. The drawback of this water-related weakening is that Rayleigh-Taylor instabilities initiate at the base of the hydrated upper plate (Arcay et al., 2005, Fig 13c), thickening the viscous blanket. Compared to simulation S1-8 without water transfers, SST is cooled by $\sim 150^{\circ} \mathrm{C}$, mimicking the coldest $P-T$ conditions inferred from $\mathrm{H}_{2} \mathrm{O} / \mathrm{Ce}$ measurements. As the convective destabilization of the overriding lithosphere is impeded if the maximum hydrous strength reduction is lower than $20^{3 / 2} \simeq 90$ (Arcay et al., 2006), a compromise could be to limit the maximum water-related weakening to 90 , instead of 350 . The asthenospheric viscosity would then be lowered by a factor varying from 4 to 19 .

\subsection{Interplate strength favouring subduction viability and reproducing cold fore- arc nose extent}

This study shows that there is no universal value of the subduction channel strength able to model realistic subduction whatever subducting plate age (i.e., successful initiation, limited compressive stresses and occurence of wet mantle melting), if crust buoyancy is $-380 \mathrm{~kg} \cdot \mathrm{m}^{-3}$ (Fig. 12). Since the best $\Delta E_{a}$ interval modelling reasonable SST is $80-120 \mathrm{~kJ} / \mathrm{mol}$ (section 6.6), crust buoyancy should not exceed $-80 /-200 \mathrm{~kg} \cdot \mathrm{m}^{-3}$ to allow young plate subduction (Fig. 7). Nevertheless, the simulation of a hot and shallow mantle wedge consistent with conditions of last equilibration of near-primary arc magmas requires a quite different range of crust strength in anhydrous conditions: $\Delta E_{a} \leq 20 \mathrm{~kJ} / \mathrm{mol}$. Moreover, the sharp transition between low to high seismic velocities delineating the cold fore-arc nose is often observed at shallow depth: $\sim 65 \mathrm{~km}$ in NE Japan and Alaska (Zhao et al., 1992; Stachnik et al., 2004; Abers et al., 2006); $\sim 45 \mathrm{~km}$ in Hikurangi (Davey and Ristau, 2011) and in the Cascadia (Zhao, 2001 ) and $<40 \mathrm{~km}$ in S Japan (Miura et al., 2003). If seismic anomalies image thermal contrasts, to model such shallow $z_{\text {coup }}$ when $A_{t} \simeq 100 \mathrm{Myr}, \Delta E_{a}$ should be set to $\sim 30-40 \mathrm{~kJ} / \mathrm{mol}$ in Alaska and NE Japan, and lower than $20 \mathrm{~kJ} / \mathrm{mol}$ in Hikurangi (Fig. 5b); in the Cascadia and S Japan where $A_{t}<25 \mathrm{Myr}, \Delta E_{a}$ should be $20-40 \mathrm{~kJ} / \mathrm{mol}$ and at most set to $20 \mathrm{~kJ} / \mathrm{mol}$, respectively (Fig. 9). The constraints from seismic tomography lead to $10 \lesssim \Delta E_{a}<40 \mathrm{~kJ} / \mathrm{mol}$, which is consistent with the range inferred from hot mantle wedge-derived melts.

Finally, two different ranges of $\Delta E_{a}$ may be underlined: $80-120 \mathrm{~kJ} / \mathrm{mol}$ and $10-$ $40 \mathrm{~kJ} / \mathrm{mol}$, that are not compatible although constraints from petro-geochemistry and geophysics were obtained on the same subduction zones. How to infer a reconciling value? Again, an extra process regulating the mantle wedge structure could be invoked, such as a decrease in mantle strength depending on $\left[\mathrm{OH}^{-}\right]$ (section 6.6). A moderate weakening ( one order of magnitude) in the hydrated 
wedge should be sufficient to simulate realistic SSTs and a shallow hot wedge core, keeping for the interplate strength the median value $\Delta E_{a}=80 \mathrm{~kJ} / \mathrm{mol}$ (simulation S1-8b, Fig. 13c-d).

\subsection{Is the down-dip extent of the subduction plane likely to be identical for worldwide subduction zones?}

In conclusion, three sets of rheological parameters are pointed out: (1) $\Delta E_{a} \sim 80-120 \mathrm{~kJ} / \mathrm{mol}$ to simulate SST derived from $\mathrm{H}_{2} \mathrm{O} /$ Ce measurements; (2) $\Delta E_{a} \sim 10-40 \mathrm{~kJ} / \mathrm{mol}$ to model the hot and shallow mantle wedge inferred from seismic tomographies and near-primary arc magmas; and (3) a median crust strength $\left(\Delta E_{a} \sim 80 \mathrm{~kJ} / \mathrm{mol}\right)$ combined to a water-related weakening. Only rheological sets (1) and (3) are compatible. In case (2), $z_{\text {coup }}$ is strongly controlled by the corner flow. As the corner flow dynamics basically depends on the incoming slab characteristics and subduction parameters (such as convergence rate), if $\Delta E_{a}=25 \pm 15 \mathrm{~kJ} / \mathrm{mol}$ then the subduction plane down-dip extent very probaly varies from a subduction zone to another. In case $(1), z_{\text {coup }}$ equals more or less the upper plate thickness: a bit shallower if $\Delta E_{a}=80 \mathrm{~kJ} / \mathrm{mol}$ ( $82 \mathrm{~km}$ if $A_{t}=100 \mathrm{Myr}$ ), or a bit deeper if $\Delta E_{a}=120 \mathrm{~kJ} / \mathrm{mol}(135 \mathrm{~km}$, Fig. $5 b)$. Hence, the down-dip extent of the subduction channel may be almost independent from subduction parameters if $\Delta E_{a}=120 \mathrm{~kJ} / \mathrm{mol}$, and moderately dependent if $\Delta E_{a}=80 \mathrm{~kJ} / \mathrm{mol}$. In case (3), $z_{\text {coup }}$ strongly depends on subduction velocity (as shown for $\Delta E_{a}=110 \mathrm{~kJ} / \mathrm{mol}$ by Arcay et al., 2008, using a mesh too coarse implying crust strengthening: the effective $\Delta E_{a}$ might have been $\sim 80 \mathrm{~kJ} / \mathrm{mol}$ ). Since rheology (3) enables to verify all the listed constraints on the mantle wedge thermal state, it may be the best choice to simulate the subduction channel strength. This implies to limit crust buoyancy to $\Delta \rho_{c} \sim-80$ kg. $\mathrm{m}^{-3}$ to allow young plate subduction (Fig. 7), assuming crust eclogitization at $\sim 17$ kbar (Bousquet et al., 1997). Besides, if $\Delta E_{a} \sim 80 \mathrm{~kJ} / \mathrm{mol}$, then partial kinematic coupling at the fore-arc base should not occur. Lastly, the rheological properties of the subduction channel estimated in this study imply that the subduction plane down-dip extent varies as a function of the subduction set-up, as suggested by the wide range of slab sub-arc depths (England et al., 2004; Syracuse and Abers, 2006, section 1). This conclusion disagrees with a single value of $z_{\text {coup }}$ universally equal to $80 \mathrm{~km}$ depth (Wada and Wang, 2009).

\section{Acknowledgement}

Comments from Satoru Honda, James Conder, an anonymous reviewer, and editor Marc Jellinek have lead to a significant improvement of the paper. Their careful reviews were greatly appreciated. Stéphane Arnal, Fabrice Grosbeau, and Josiane Tack are acknowledged for the maintenance and development of the cluster of computing nodes on which all numerical experiments were performed. I deeply thank Matthieu Lilla, Izia L. and Elio L., as well as Marc RegnyDemery for their support that was essential. Figure 9 is made using GMT (Wessel and Smith, 1991). This work has been funded by the CNRS-INSU 
(National Institute of Universe Science) program "TelluS-SYSTER" (2011, 2015

and 2016).

\section{References}

Abers, G. A., van Keken, P. E., Kneller, E. A., Ferris, A., Stachnik, J. C., 2006. The thermal structure of subduction zones constrained by seismic imaging: Implications for slab dehydration and wedge flow. Earth and Planetary Science Letters 241, 387 - 397, doi:10.1016/j.epsl.2005.11.055.

URL http://www.sciencedirect.com/science/article/pii/S0012821X05008290

Agrusta, R., van Hunen, J., Goes, S., 2014. The effect of metastable pyroxene on the slab dynamcis. Geophys. Res. Lett. 41, 8800-8808, doi:10.1002/2014GL062159.

Andrews, E. R., Billen, M. I., 2009. Rheologic controls on the dynamics of slab detachment. Tectonophysics 464 (14), 60 - 69, interpreting the tectonic evolution of Pacific Rim margins using plate kinematics and slab window volcanism.

URL http://www.sciencedirect.com/science/article/pii/S0040195107003186

Arcay, D., 2012. Dynamics of interplate domain in subduction zones: influence of rheological parameters and subducting plate age. Solid Earth 3 (2), 467488.

URL http://www.solid-earth.net/3/467/2012/

Arcay, D., Doin, M.-P., Tric, E., 2006. Overriding plate thinning in subduction zones: Localized convection induced by slab dehydration. Geochem. Geophys. Geosyst. 7, doi:10.1029/2005GC001061.

Arcay, D., Doin, M.-P., Tric, E., Bousquet, R., 2007a. Influence of the precollisional stage on the subduction dynamics and the burried crust thermal state: Insights from numerical simulations. Tectonophysics 441, 27-45, doi:10.1016/j.tecto.2007.06.001.

Arcay, D., Lallemand, S., Doin, M.-P., 2008. Back-arc strain in subduction zones: Statistical observations vs. numerical modelling. Geochem. Geophys. Geosyst. 9, doi:10.1029/2007GC001875.

Arcay, D., Tric, E., Doin, M.-P., 2005. Numerical simulations of subduction zones: Effect of slab dehydration on the mantle wedge dynamics. Phys. Earth Planet. Inter. 149, 133-153.

Arcay, D., Tric, E., Doin, M.-P., 2007b. Slab surface temperature in subduction zones: Influence of the interplate decoupling depth and upper plate thinning processes. Earth Planet. Sci. Lett. 255, 324-338, doi:10.1016/j.epsl.2006.12.027. 
Bartels, K., Kinzler, R., Grove, T., 1991. High pressure phase relations of primitive high-alumina basalts from Medicine Lake Volcano, Northern California. Contrib. Mineral. Petrol. 108, 253-270.

Bird, P., 2003. An updated digital model of plate boundaries. Geochem. Geophys. Geosyst. 4, doi:10.1029/2001GC000252.

Bousquet, R., Goffé, B., Henry, P., Le Pichon, X., Chopin, C., 1997. Kinematic, thermal and petrological model of the Central Alps: Lepontine metamorphism in the upper crust and eclogitisation of the lower crust. Tectonophysics 273, $105-127$.

Brace, W., Kohlstedt, D., 1980. Limits on lithospheric stress imposed by laboratory experiments. J. Geophys. Res. 85, 6348-6252.

Christensen, U. R., 1992. An Eulerian technique for thermomechanical modeling. J. Geophys. Res. 97, 2015-2036.

Conder, J., 2005. A case for hot slab surface temperatures in numerical viscous flow models of subduction zones with an improved fault zone parameterization. Phys. Earth Planet. Inter. 149, 155-164.

Cooper, L., Ruscitto, D., Plank, T., Wallace, P., Syracuse, E., Manning, C., 2012. Global variations in $\mathrm{H}_{2} \mathrm{O} / \mathrm{Ce}$ : 1 . Slab surface temperatures beneath volcanic arcs. Geochem. Geophys. Geosyst. 13, doi:10.1029/2011GC003902.

Crameri, F., Tackley, P., 2015. Parameters controlling dynamically selfconsistent plate tectonics and single-sided subduction in global models of mantle convection. J. Geophys. Res. 120, 3680-3706, doi:10.1002/2014JB011664.

Crameri, F., Tackley, P., Meilick, I., Gerya, T., Kaus, B., 2012. A free plate surface and weak oceanic crust produce single-sided subduction on Earth. Geophys. Res. Lett. 39, 10.1029/2011GL050046.

Davey, F., Ristau, J., 2011. Fore-arc mantle wedge seismicity under northeast New Zealand. Tectonophysics 509, 272-279, doi:10.1016/j.tecto.2011.06.017.

Deubelbeiss, Y., Kaus, B., 2008. Comparison of Eulerian and Lagrangian numerical techniques for the Stokes equations in the presence of strongly varying viscosity. Phys. Earth Planet. Inter. 171 (12), 92 - 111, doi:10.1016/j.pepi.2008.06.023.

Doin, M.-P., Henry, P., 2001. Subduction initiation and continental crust recycling: the roles of rheology and eclogitization. Tectonophysics 342, 163-191.

Draper, D., Johnston, A., 1992. Anhydrous P-T phase relations of an Aleutian high- $\mathrm{MgO}$ basalt: An investigation of the role of olivine-liquid reaction in the generation of arc high-alumina basalts. J. Geophys. Res. 112, 501-519. 
Duarte, J. C., Schellart, W. P., Cruden, A. R., 2015. How weak is the subduction zone interface? Geophysical Research Letters 42 (8), 2664-2673, doi:10.1002/2014GL062876.

URL http://dx.doi.org/10.1002/2014GL062876

Duretz, T., May, D. A., Gerya, T. V., Tackley, P. J., 2011. Discretization errors and free surface stabilization in the finite difference and marker-in-cell method for applied geodynamics: A numerical study. Geochemistry, Geophysics, Geosystems 12 (7), n/a-n/a, q07004.

URL http://dx.doi.org/10.1029/2011GC003567

Eberle, M., Grasset, O., Sotin, C., 2002. A numerical study of the interaction between the mantle wedge, the subducting slab, and overriding plate. Phys. Earth Planet. Inter. 134, 191-202.

Elkins Tanton, L., Grove, T., Donnelly-Nolan, J., 2001. Hot, shallow melting under the Cascades volcanic arc. Geology 29, 631-634.

England, P., Engdahl, R., Thatcher, W., 2004. Systematic variation in the depths of slabs beneath arc volcanoes. Geophys. J. Int. 156, 377-408.

England, P., Katz, R., 2010. Melting above the anhydrous solidus controls the location of volcanic arcs. Nature 467, 700-703, doi:10.1038/nature09417.

England, P., Wilkins, C., 2004. A simple analytical approximation to the temperature structure in subduction zones. Geophys. J. Int. 159, 1138-1154, doi:10.1111/j.1365-246X.2004.02419.x.

Falloon, T., Danyushevsky, L., 2000. Melting of refractory mantle at 1.5, 2 and 2.5 gpa under anhydrous and $\mathrm{H}_{2} \mathrm{O}$-undersaturated conditions: implications for the petrogenesis of high-Ca boninites and the influence of subduction components on mantle melting. J. Petrology. 41, 257-283.

Furukawa, Y., 1993. Depth of the decoupling plate interface and thermal structure under arcs. J. Geophys. Res. 98, 20005-20013.

Garel, F., Goes, S., Davies, D. R., Davies, J. H., Kramer, S. C., Wilson, C. R., 2014. Interaction of subducted slabs with the mantle transition-zone: A regime diagram from 2-d thermo-mechanical models with a mobile trench and an overriding plate. Geochem. Geophys. Geosyst. 15 (5), 1739-1765, doi:10.1002/2014GC005257.

URL http://dx.doi.org/10.1002/2014GC005257

Gerya, T., Connolly, J., Yuen, D., 2008. Why is terrestrial subduction one-sided? Geology 36, 43-46.

Gleason, G., Tullis, J., 1995. A flow law for dislocation creep of quartz aggregates determined with the molten salt cell. Tectonophysics 247, 1-23. 
Green, D., 1973. Experimental melting studies on a model mantle composition at high pressure under water-undersaturated conditions. Earth Planet. Sci. Lett. 19, 37-53.

Green, D., Hibberson, W., Kovacs, I., Rosenthal, A., 2010. Water and its influence on on the lithosphere-asthenosphere boundary. Nature 467, 448-451.

Grove, T., Chatterjee, N., Parman, S., Médard, E., 2004. The influence of $\mathrm{H}_{2} \mathrm{O}$ on mantle wedge melting. Earth Planet. Sci. Lett. 219, 173-187.

Grove, T., Elkins-Tanton, L., Parman, S., Chatterjee, N., Muentener, O., Gaetani, G., 2003. Fractional crystalization and mantle-melting controls on calcalkaline differenciation trends. Contrib. Mineral. Petrol. 145, 515-533.

Grove, T., Till, C., Krawczynski, M., 2012. The role of $\mathrm{H}_{2} \mathrm{O}$ in subduction zone magmatism. Annu. Rev. Earth Planet. Sci. 40, 413-439, doi:10.1146/annurevearth-042711-105310.

Grove, T., Till, C., Lev, E., Chatterjee, N., Médard, E., 2009. Kinematic variables and water transport control the formation and location of arc volcanoes. Nature 459, 694-697, doi:10.1038/nature08044.

Gurnis, M., Hager, B., 1988. Controls on the structure of subducted slabs. Nature 335, 317-321.

Hacker, B. R., Kelemen, P. B., Behn, M. D., 2011. Differentiation of the continental crust by relamination. Earth Planet. Sci. Lett. 307, 501 - 516, doi:http://dx.doi.org/10.1016/j.epsl.2011.05.024.

URL http: //www.sciencedirect.com/science/article/pii/S0012821X11003074

Hesse, M., Grove, T., 2003. Absakorites from the western Mexican vocalnic belt: constraints on mantle wedge conditions. Contrib. Mineral. Petrol. 146, 10-27.

Heuret, A., Lallemand, S., 2005. Plate motions, slab dynamics and back-arc deformation. Phys. Earth Planet. Inter. 149, 31-51.

Hirauchi, K., Katayama, I., 2013. Rheological contrast between serpentine species and implications for slab-mantle wedge decoupling. Tectonophysics 608, 545 - 551, doi:10.1016/j.tecto.2013.08.027.

URL http: //www.sciencedirect.com/science/article/pii/S0040195113005180

Hoffman, P., Ranalli, G., 1988. Archean oceanic flake tectonics. Geophys. Res. Lett. 15, 1077-1080.

Honda, S., 1985. Thermal structure beneath Tohoku, northeast Japan-a case study for understanding the detailed thermal structure of the ubduction zone. Tectonophysics 112, 69-102.

Iwamori, H., Richardson, C., Maruyama, S., 2007. Numerical modeling of thermal structure, circulation of $\mathrm{H}_{2} \mathrm{O}$, and magmatism-metamorphism in subduction zones: Implications for evolution of arcs. Gondwana Res. 11, 109-119. 
Jarrard, R., 1986. Relations among subduction parameters. Rev. Geophys. 24, $217-284$.

Karato, S.-I., Paterson, M., FitzGerald, J., 1986. Rheology of synthetic olivine aggregates: influence of grain size and water. J. Geophys. Res. 91, 8151-8176.

Kelemen, P., Rilling, J., Parmentier, E., Mehl, L., Hacker, B. R., 2003. Thermal structure due to solid-state flow in the mantle wedge beneath arcs. In: Eiler, J. (Ed.), Inside the Subduction factory. Vol. 138 of Geophys. Monogr. Ser. AGU, Washington D.C., pp. 293-311.

Kincaid, C., Sacks, I., 1997. Thermal and dynamical evolution of the upper mantle in subduction zones. J. Geophys. Res. 102, 12,295-12,315.

King, S. D., Hager, B. H., 1990. The relationship between plate velocity and trench viscosity in Newtonian and power-law subduction calculations. Geophys. Res. Lett. 17 (13), 2409-2412.

URL http://dx.doi.org/10.1029/GL017i013p02409

Kirby, S., 1983. Rheology of the lithosphere. Rev. Geophys. 21, 1458-1487.

Kneller, E., van Keken, P., Karato, S., Park, J., 2005. B-type olivine fabric in the mantle wedge: Insights from high-resolution non-Newtonian subduction zone models. Earth Planet. Sci. Lett. 237, 781-797.

Kneller, E., van Keken, P., Katayama, I., Karato, S., 2007. Stress, strain, and B-type olivine fabric in the fore-arc mantle: Sensitivity tests using high-resolution steady-state subduction zone models. J. Geophys. Res. 112, 10.1029/2006JB004544.

Kohlstedt, D., Evans, B., Mackwell, S., 1995. Strength of the lithosphere: Constraints imposed by laboratory experiments. J. Geophys. Res. 100, 1758717602.

Kopitzke, U., 1979. Finite element convection models: comparison of shallow and deep mantle convection, and temperatures in the mantle. J. Geophys. 46, $97-121$.

Kushiro, I., Syono, Y., Akimoto, S., 1968. Melting of a peridotite nodule at high pressures and high water pressurs. J. Geophys. Res. 73, 6023-6029.

Mackwell, S., , Zimmerman, M., Kohlstedt, D., 1998. High-temperature deformation of dry diabase with applications to tectonics on Venus. J. Geophys. Res. 103, 975984.

Marques, F., Kaus, B., 2016. Speculations on the impact of catastrophic subduction initiation on the earth system. Journal of Geodynamics 93, 1 16, doi:10.1016/j.jog.2015.09.003.

URL http://www.sciencedirect.com/science/article/pii/S0264370715300211 
Maunder, B., van Hunen, J., Magni, V., Bouilhol, P., 2016. Relamination of mafic subducting crust throughout earth's history. Earth and Planetary Science Letters 449, 206 - 216, doi:10.1016/j.epsl.2004.10.040.

URL http://www.sciencedirect.com/science/article/pii/S0012821X16302679

Millholen, G., Irving, A., Wyllie, P., 1974. Melting interval of peridotite with 5.7 per cent water to 30 kilobars. J. Geol 82, 575-587.

Miura, S., Kodaira, S., Nakanishi, A., Tsuru, T., Takahashi, N., Hirata, N., Kaneda, Y., 2003. Structural characteristics controlling the seismicity of southern Japan Trench fore-arc region, revealed by ocean bottom seismographic data. Tectonophysics 363, 79-102, doi:10.1016/S0040-1951(02)006558.

Mysen, B., Boettcher, A., 1975. Melting of a hydrous mantle: I. Phase relations of natural peridotite at high-pressures and temperatures with controlled activities of water, carbon dioxide, and hydrogen. J. Petrology. 16, 20-48.

Peacock, S., Hyndman, R., 1999. Hydrous minerals in the mantle wedge and the maximum depth of subduction thrust earthquakes. Geophys. Res. Lett. $26,2517-2520$.

Plank, T., Cooper, L., Manning, C., 2009. Emerging geothermometers for estimating slab surface temperatures. Nat. Geosci. 2, $611-615$, doi:10.1038/NGEO614.

Quinquis, M., Buiter, S., Ellis, S., 2011. The role of boundary conditions in numerical models of subduction dynamics. Tectonophysics 497, 57-70.

Ranalli, G., 1995. Rheology of the Earth. Chapman and Hall, London, 2nd edn.

Ranalli, G., Murphy, D., 1987. Rheological stratification of the lithosphere. Tectonophysics 132, 281-295.

Ribe, N., Christensen, U., 1994. Three-dimensional modeling of plumelithosphere interaction. J. Geophys. Res. 99, 699-682.

Samuel, H., Evonuk, M., 2010. Modeling advection in geophysical flows with particle level sets. Geochem. Geophys. Geosyst. 11 (8), q08020.

URL http://dx.doi.org/10.1029/2010GC003081

Schmeling, H., Babeyko, A., Enns, A., Faccenna, C., Funiciello, F., Gerya, T., Golabek, G., Grigull, S., Kaus, B., Morra, G., Schmalholz, S., van Keken, J., 2008. A benchmark comparison of spontaneous subduction models - Tonwards a free surface. Phys. Earth Planet. Inter. 171, 198-223.

Schmidt, M., Poli, S., 1998. Experimentally based water budgets for dehydrating slabs and consequences for arc magma generation. Earth Planet. Sci. Lett. 163, 361-379. 
Stachnik, J., Abers, G., Christensen, D., 2004. Seismic attenuation and mantle wedge temperatures in the Alaska subduction zone. J. Geophys. Res. 109, doi:10.1029/2004JB003018.

Syracuse, E., Abers, G., 2006. Global compilation of variations in slab depth beneath arc volcanoes and implications. Geochem. Geophys. Geosyst. 7, doi:10.1029/2005GC001045.

Syracuse, E., van Keken, P. E., Abers, G., 2010. The global range of subduction zones thermal models. Phys. Earth Planet. Inter. 183, 73-90.

Tackley, P., 2000. Self-consistent generation of tectonics plates in timedependent, three-dimensional mantle convection simulation. 1. Pseudoplastic yielding. Geochem. Geophys. Geosyst. 1, doi:10.1029/2000GC000036.

Tatsumi, Y., 1981. Melting experiments on a high-magnesium andesite. Earth Planet. Sci. Lett. 54, 357-365.

Tatsumi, Y., Sakuyama, M., Fukuyama, H., Hushiro, I., 1983. Generation of arc baslt magmas and thermal struction of the mantle wedge in subduction zones. J. Geophys. Res. 88, 5815-5825.

Till, C. B., Grove, T. L., Withers, A. C., 2012. The beginnings of hydrous mantle wedge melting. Contrib. Mineral. Petrol. 163 (4), 669-688, doi:10.1007/s00410-011-0692-6.

URL http://dx.doi.org/10.1007/s00410-011-0692-6

Turcotte, D., Schubert, G., 1982. Geodynamics: Applications of continuum physics to geological problems, 2nd Edition. Cambridge University Press, New York.

van Heck, H., Tackley, P., 2008. Planforms of self-consistently generated plates in 3d spherical geometry. Geophys. Res. Lett. 35, doi:10.1029/2008GL035190.

van Keken, P., Kiefer, B., Peacock, S., 2002. High-resolution models of subduction zones: implications for mineral dehydration reactions and the transport of water into the deep mantle. Geochem. Geophys. Geosyst. 3, doi:10.1029/2001GC000256.

van Keken, P., King, S., Schmeling, H., Christensen, U., Neumeister, D., Doin, M.-P., 1997. A comparison of methods for the modeling of thermochemical convection. J. Geophys. Res. 102, 22477-22495.

van Keken, P. E., Hacker, B. R., Syracuse, E. M., Abers, G. A., 2011. Subduction factory: 4. depth-dependent flux of h2o from subducting slabs worldwide. Journal of Geophysical Research: Solid Earth 116 (B1), doi:10.1029/2010JB007922.

URL http://dx.doi.org/10.1029/2010JB007922 
Vogt, K., Castro, A., Gerya, T., 2013. Numerical modeling of geochemical variations caused by crustal relamination. Geochemistry, Geophysics, Geosystems 14 (2), 470-487, doi:10.1002/ggge.20072.

URL http://dx.doi.org/10.1002/ggge.20072

Wada, I., King, S., 2015. Dynamics of subducting slabs: Numerical modeling and constraints from seismology, geoid, topography, geochemistry, and petrology. In: Schubert, G., Bercovici, D. (Eds.), Treatise on Geophysics, Second Edition. Mantle Dynamics, vol.7. Elsevier, Oxford, pp. 339-391.

Wada, I., Wang, K., 2009. Common depth of slab-mantle decoupling: Reconciling diversity and uniformity of subduction zones. Geochem. Geophys. Geosyst. 10, doi:10.1029/2009GC002570.

Wada, I., Wang, K., He, J., Hyndman, R., 2008. Weakening of the subduction interface and its effects on surface heat flow, slab dehydration, and mantle wedge serpentinization. J. Geophys. Res. 113, doi/10.1029/2007JB005190.

Wang, H., Agrusta, R., van Hunen, J., 2015. Advantages of a conservative velocity interpolation (CVI) scheme for particle-in-cell methods with application in geodynamic modeling. Geochem. Geophys. Geosyst. 16, doi:10.1002/2015GC005824.

Watt, S. F. L., Pyle, D. M., Mather, T. A., Naranjo, J. A., 2013. Arc magma compositions controlled by linked thermal and chemical gradients above the subducting slab. Geophysical Research Letters 40 (11), 2550-2556, doi:10.1002/grl.50513.

URL http://dx.doi.org/10.1002/grl.50513

Wessel, P., Smith, W., 1991. Free software helps map and display data. Eos Trans. AGU 72 (41), 445-446.

Wilks, K., Carter, N., 1990. Rheology of some continental lower crustal rocks. Tectonophysics 182, 57-77.

Zhao, D., 2001. Seismological structure of subduction zones and its implications for arc magmatism and dynamics. Phys. Earth Planet. Inter. 127, 197-214.

Zhao, D., Hasegawa, A., Horiuchi, S., 1992. Tomographic imaging of $P$ - and $S$-wave velocity structure beneath Northeastern Japan. J. Geophys. Res. 97, 19,909-19,928. 


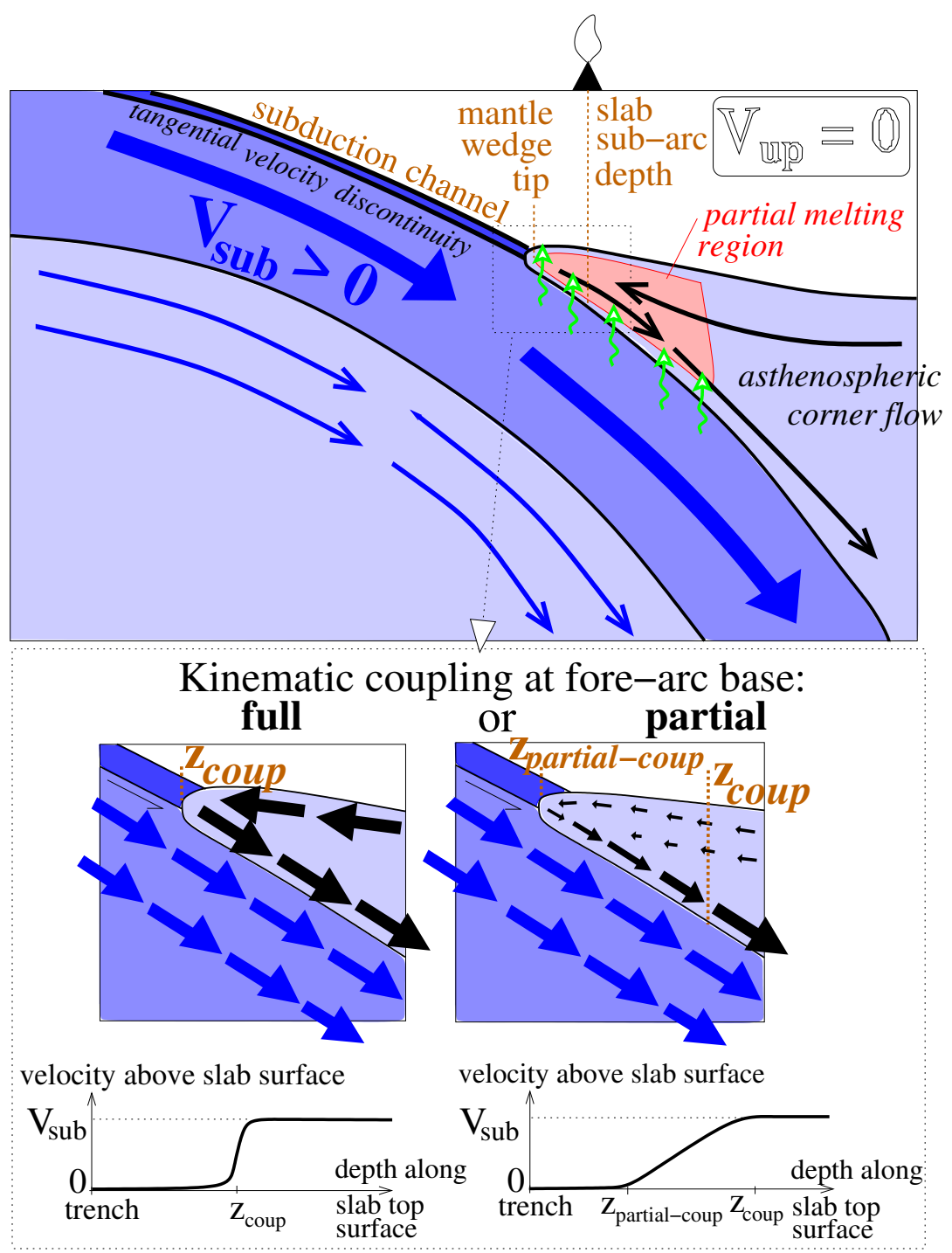

Figure 1: Sketch of the subduction interplate and definitions of the main terms used to describe the mantle wedge structure (in brown). Green ascending arrows represent fluids expelled by the dehydrating slab. The red area depicts the mantle wedge part hot enough for melting in wet conditions. In the bottom panel, two kinds of kinematic coupling between the subducting slab and the overlying mantle are considered: In case of full coupling, velocities at the slab surface are close to the subduction speed as soon as the down-dip extent of the subduction channel is crossed, defining $z_{\text {coup }}$ there. In case of partial kinematic coupling, velocities at the slab surface are low at the subduction channel end and increase downwards. $z_{\text {partial-coup }}$ is defined as the shallowest depth where velocities at slab surface are low but different from zero, while $z_{\text {coup }}$ is shifted deeper at the level where overlying mantle velocities reach the subduction speed. 


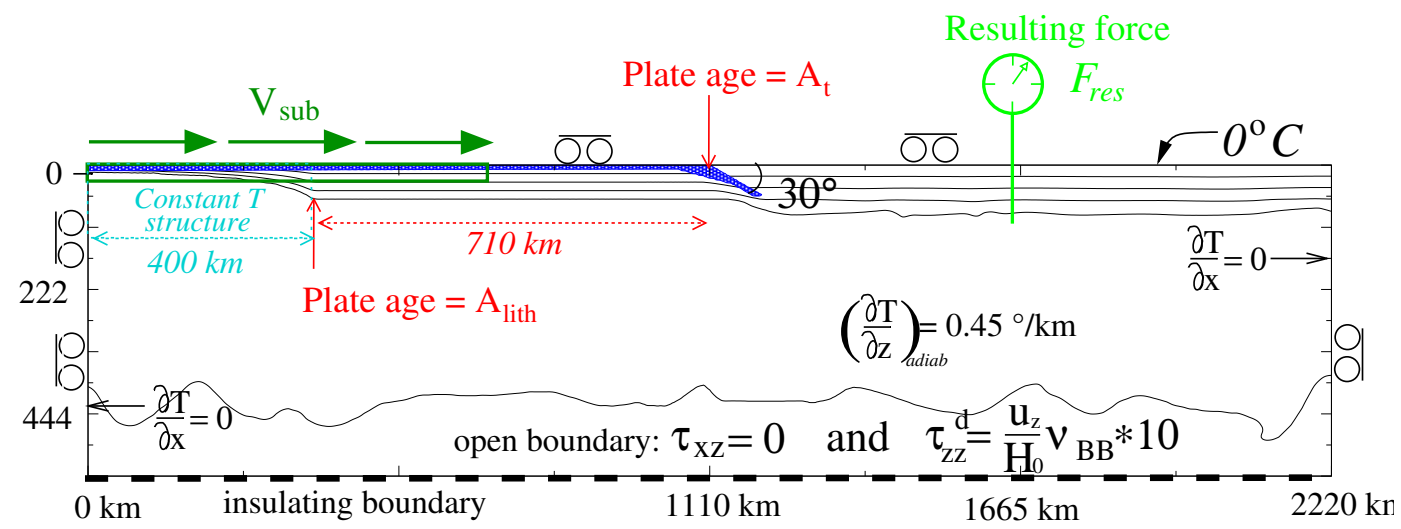

Figure 2: Kinematic and thermal boundary conditions and initial thermal state. The subducting plate velocity, $v_{\text {sub }}$, is imposed on a $832 \mathrm{~km}$ wide and $13 \mathrm{~km}$ deep domain (green box), counted from the box left-hand side and from the box surface. One isotherm every $400^{\circ}$ C. The weak layer geometry imposed at simulation start is displayed in dark blue. The temperature field constantly maintained in the light blue dashed area simulates the lithosphere cooling from its formation at the ridge (top left corner) until a chosen lithosphere age, $A_{\text {lith }}$, reached $400 \mathrm{~km}$ far away. A vertical resistance against flow is modelled along the open bottom box boundary, by mimicking a viscosity jump 10 times higher below (Ribe and Christensen, 1994; Arcay, 2012): $\tau_{z z}^{d}$ is the deviatoric vertical stress, $u_{z}$ is the vertical velocity, and $\nu_{B B}$ the viscosity at box bottom. 

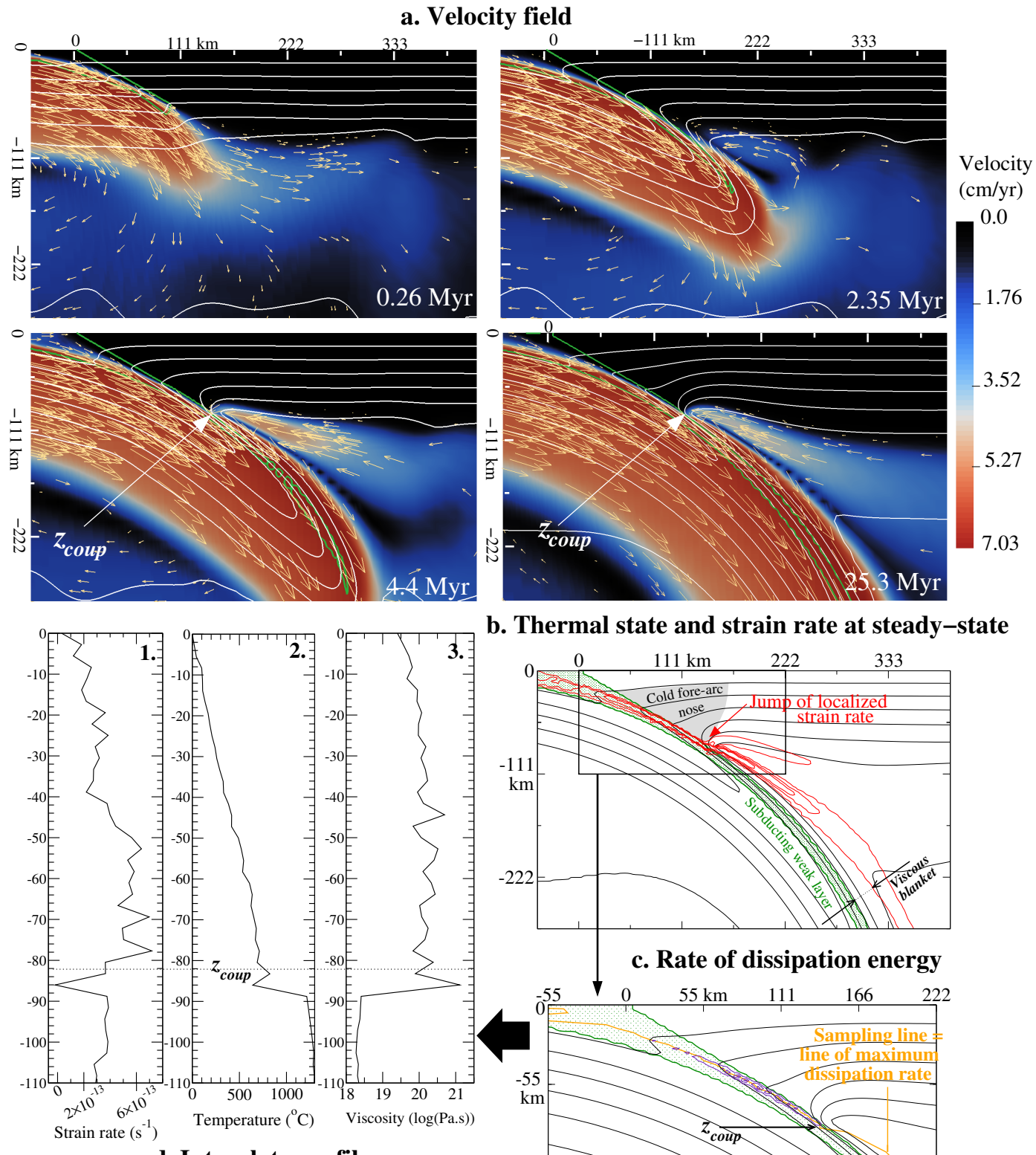

b. Thermal state and strain rate at steady-state

d. Interplate profiles

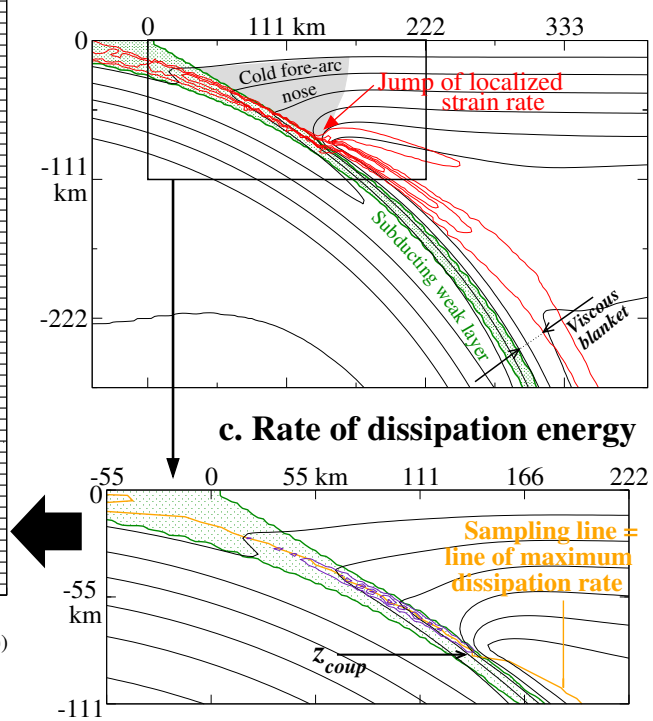

Figure 3: Close-up on the subduction structure obtained in simulation S1-8 (Table 3). (a) Thermal state (one white isotherm every $200^{\circ} \mathrm{C}$ ), composition (oceanic crust outlined by the green contour) and velocity field at different time steps. The trench is located at the abscissa $x=0 \mathrm{~km}$. (b) Thermal structure and strain rate distribution at steady-state $(26 \mathrm{Myr}$ of convergence). One red outline every $8 \times 10^{-14} \mathrm{~s}^{-1}$. (c): Close-up on the subduction interface. The interplate sampling line (orange line) joins points of maximum dissipation energy rates (see the text for details). Outlines of dissipation energy rate (purple lines) are depicted every $20 \mu \mathrm{W} \cdot \mathrm{m}^{-3}$. Panel(d): Profiles interpolated along the interplate sampling line of, from left to right, (1) second invariant of strain rate tensor, (2) temperature, and (3) viscosity. 


\section{a. Low resolution close to the coupling depth}
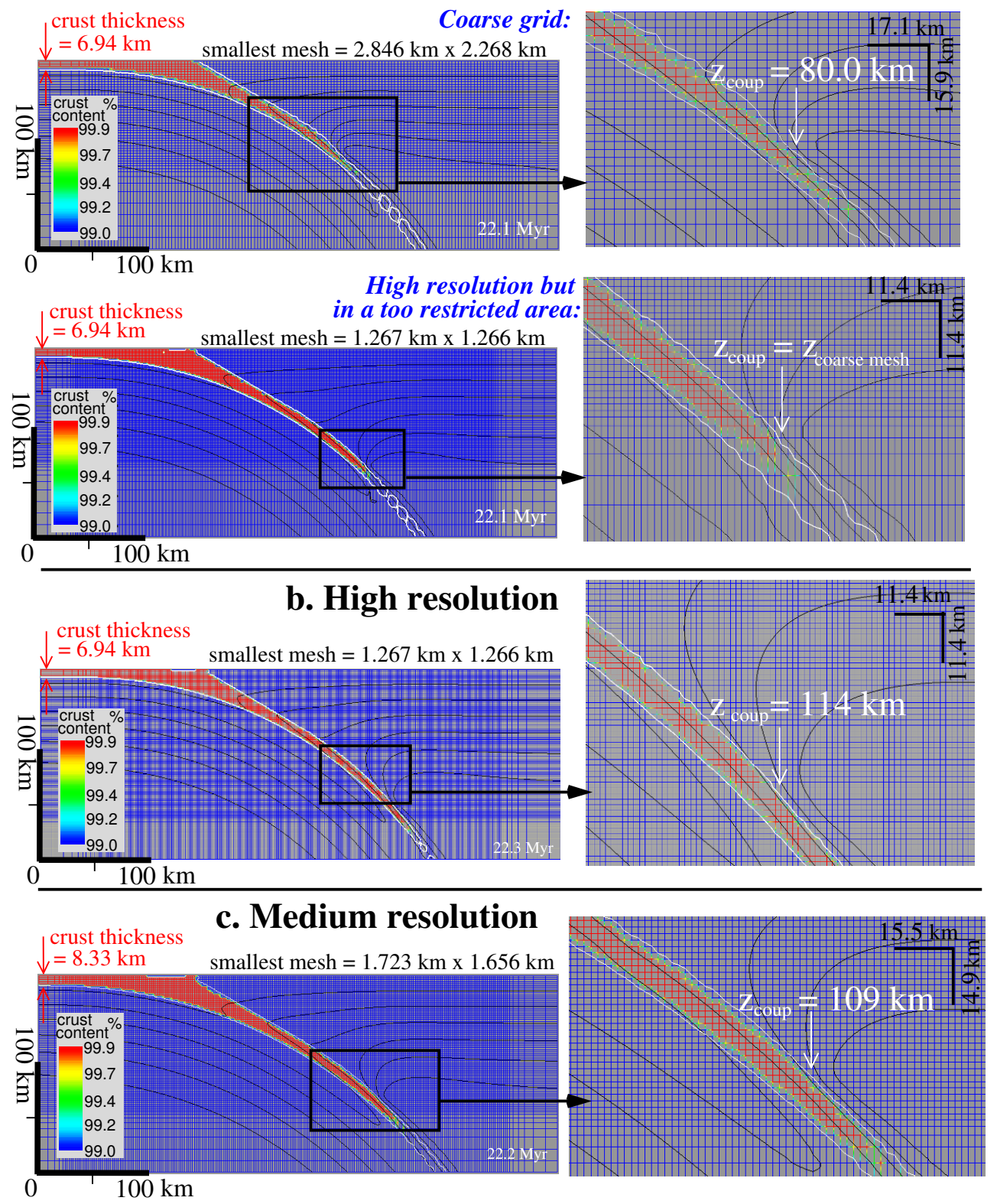

Figure 4: Influence of grid resolution and weak layer thickness on the down-dip extent of the decoupling interface: Zooms on the subduction structure at steady-state. Isotherms (black lines) every $200^{\circ} \mathrm{C}$. The rectangular Eulerian mesh is coloured as a function of crust content at computational nodes, by highlighting very high contents in crust material (>99.0\%). Within the white line the content in weak oceanic crust at Eulerian nodes is greater than $49.0 \%$. Panel (a): Simulation S1-10a (Table 3), performed with the coarsest mesh LR (Table 1) and simulation S1-10b performed with the finest mesh HRlim. Panel (b) Simulation S1-10c, computed with the finest mesh HR. Panel (c): Simulation S1-10d, performed with mesh MHR
of intermediate resolution. 


\section{a. Simulated crust strength compared to experimental laws}

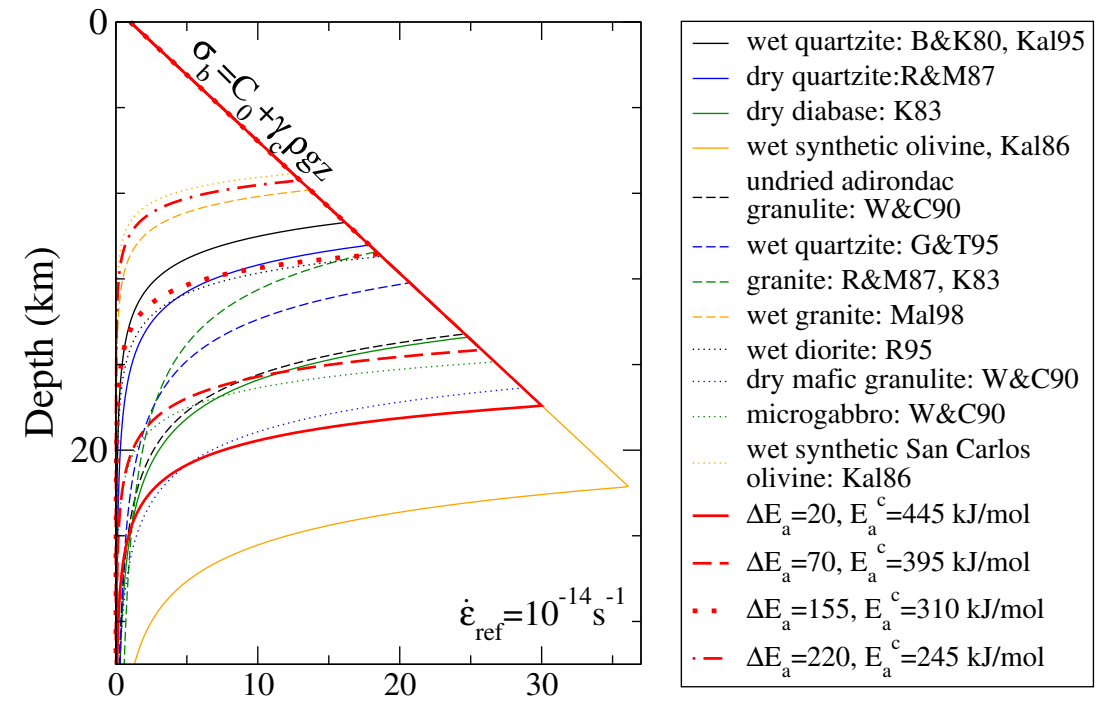

Second invariant of the stress tensor (MPa)

b. $z_{\text {coup }}$ dependence in crust ductile strength

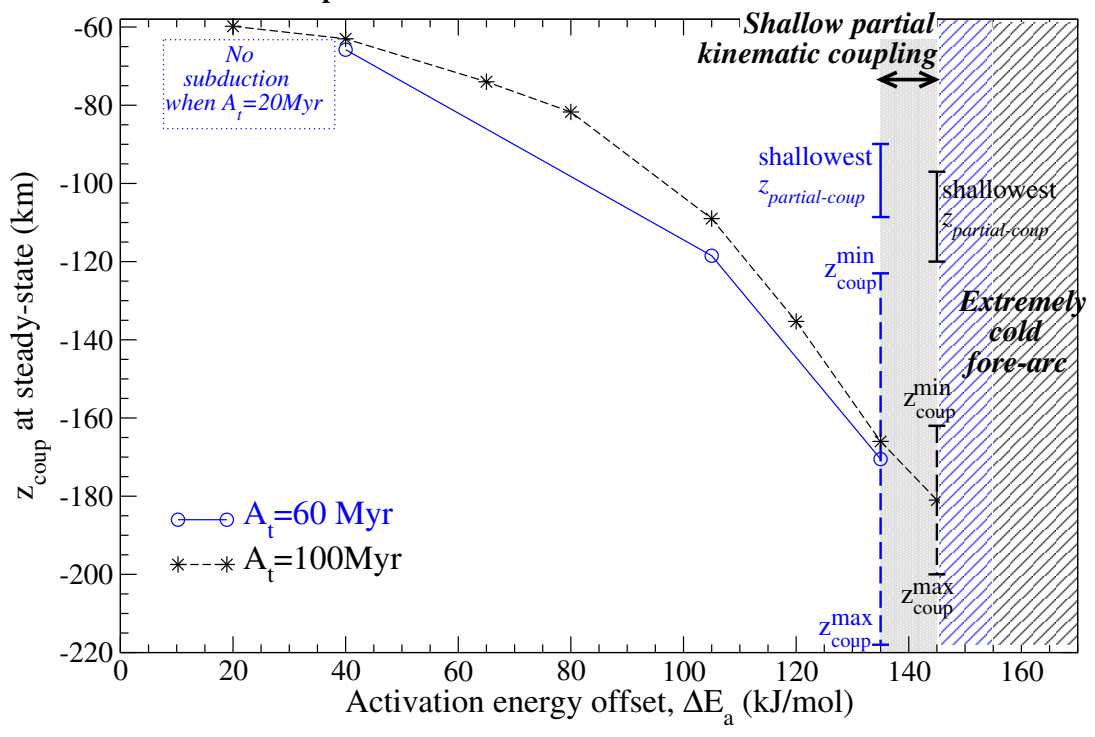

Figure 5: (a) Simulated interplate strength for different values of $\Delta E_{a}$. Stress profiles are computed with the interplate geotherm depicted in Fig. 3c1 and with a constant strain rate of $10^{-14} \mathrm{~s}^{-1}$. "B\&K80": Brace and Kohlstedt (1980), "Kal95": Kohlstedt et al. (1995), "R\&M87": Ranalli and Murphy (1987), "K83": Kirby (1983), "Mal98": Mackwell et al. (1998), "W\&C90": Wilks and Carter (1990), "G\&T95": Gleason and Tullis (1995), "R95": Ranalli (1995), "Kal86": Karato et al. (1986). (b) Down-dip extent of the interplate channel, $z_{\text {coup }}$, as a function of $\Delta E_{a}$, for $A_{t}$ set to $100 \mathrm{Myr}$ and $60 \mathrm{Myr}$. The $\Delta E_{a}$ range for which partial kinematic couling is modelled is depicted in grey, and the range over which $z_{\text {coup }}$ and $z_{\text {partial-coup }}$ vary through time by dashed and solid lines, respectively. In hachured areas, $z_{\text {coup }}$ is mesh-dependent and located at $25033 \mathrm{~h}$ depth, yielding an excessively cold fore-arc structure. 


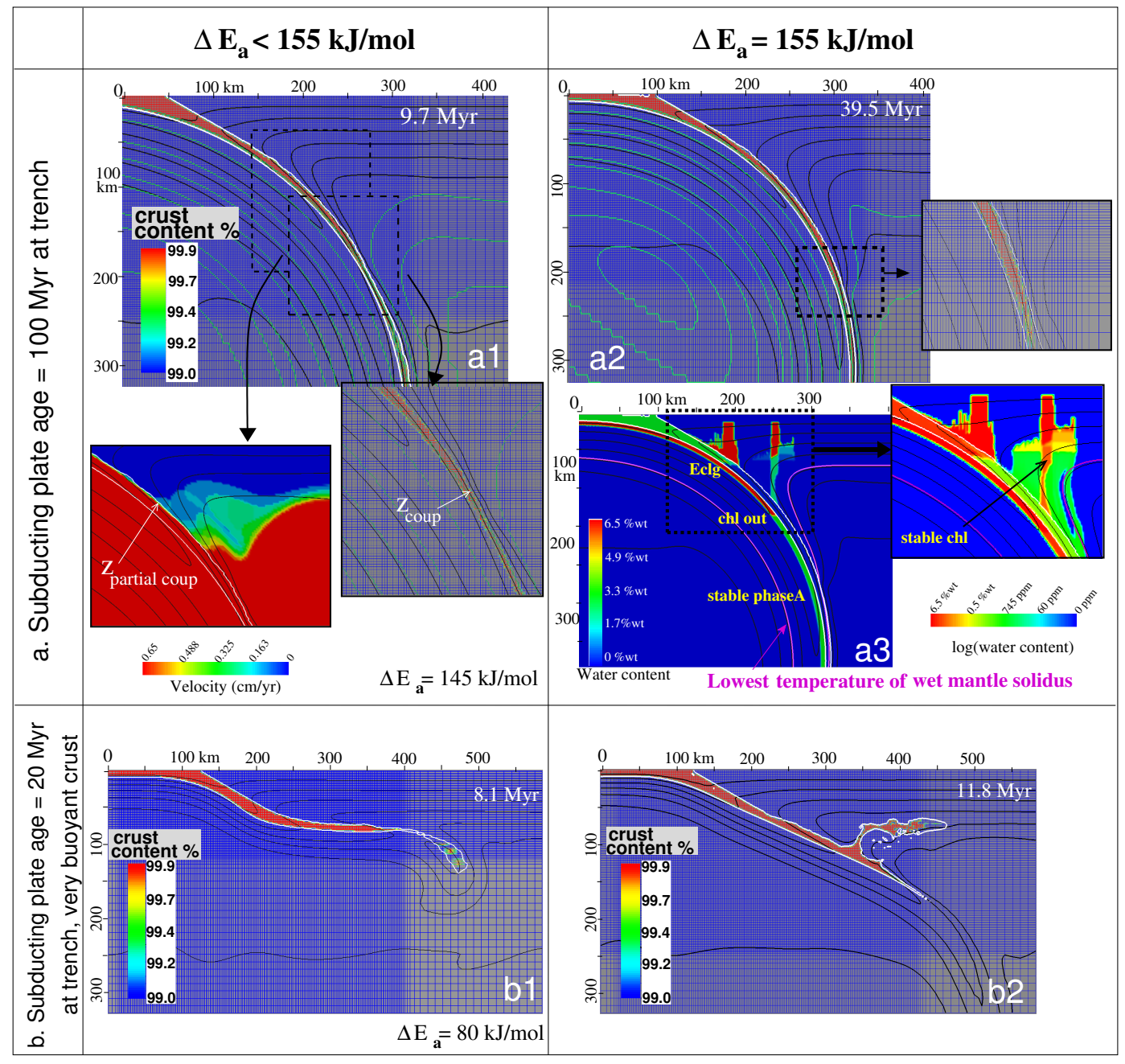

Figure 6: Influence of the crustal strength reduction, $\Delta E_{a}$, on subduction mode. One black isotherm every $200^{\circ} \mathrm{C}$. The crust content at Eulerian nodes is $>49.0 \%$ within the white outline. The numerical mesh is colored as a function of crust content, by focusing on very high contents (>99 \%). Panel (a): Subduction mode with $A_{t}=20$ Myr depending on $\Delta E_{a}$ if the oceanic crust is very buoyant $\left(\Delta \rho_{c}=-380 \mathrm{~kg} \cdot \mathrm{m}^{-3}\right.$, a1: simulation $\mathrm{S} 2-8 \mathrm{a}$, and a2: simulation $\mathrm{S} 2-$ 15a). Panel (b): Subduction of an old lithosphere for high $\Delta E_{a}$. Stream function (green outlines) is depicted every $0.2 \mathrm{~cm}^{2} / \mathrm{yr}$ counted from $-1.7 \mathrm{~cm}^{2} / \mathrm{yr}$. Left (b1): $\Delta E_{a}=145$ $\mathrm{kJ} / \mathrm{mol}$ (simulation S1-14, Table 3). In the inset, the velocity color scale is saturated to $0.65 \mathrm{~cm} / \mathrm{yr}$. Right (b2): $\Delta E_{a}=155 \mathrm{~kJ} / \mathrm{mol}$ (simulation $\left.\mathrm{S} 1-15\right)$. (b3): same simulation but including water transfer computation. The pink line is the $980^{\circ} \mathrm{C}$ isotherm, i.e., the lowest solidus temperature for a water-saturated peridotite. "Eclg": slab dehydration triggered by the gabbroic crust eclogitization. "Chl out": water expelling by chlorite destabilisation within the initially serpentinised mantle layer. "Stable phase A": water retention in the subducting mantle as a result of phase A formation when serpentine breaks down. In the bottom inset, the logarithmic water content color scale highlights very low water amounts in the mantle wedge. 

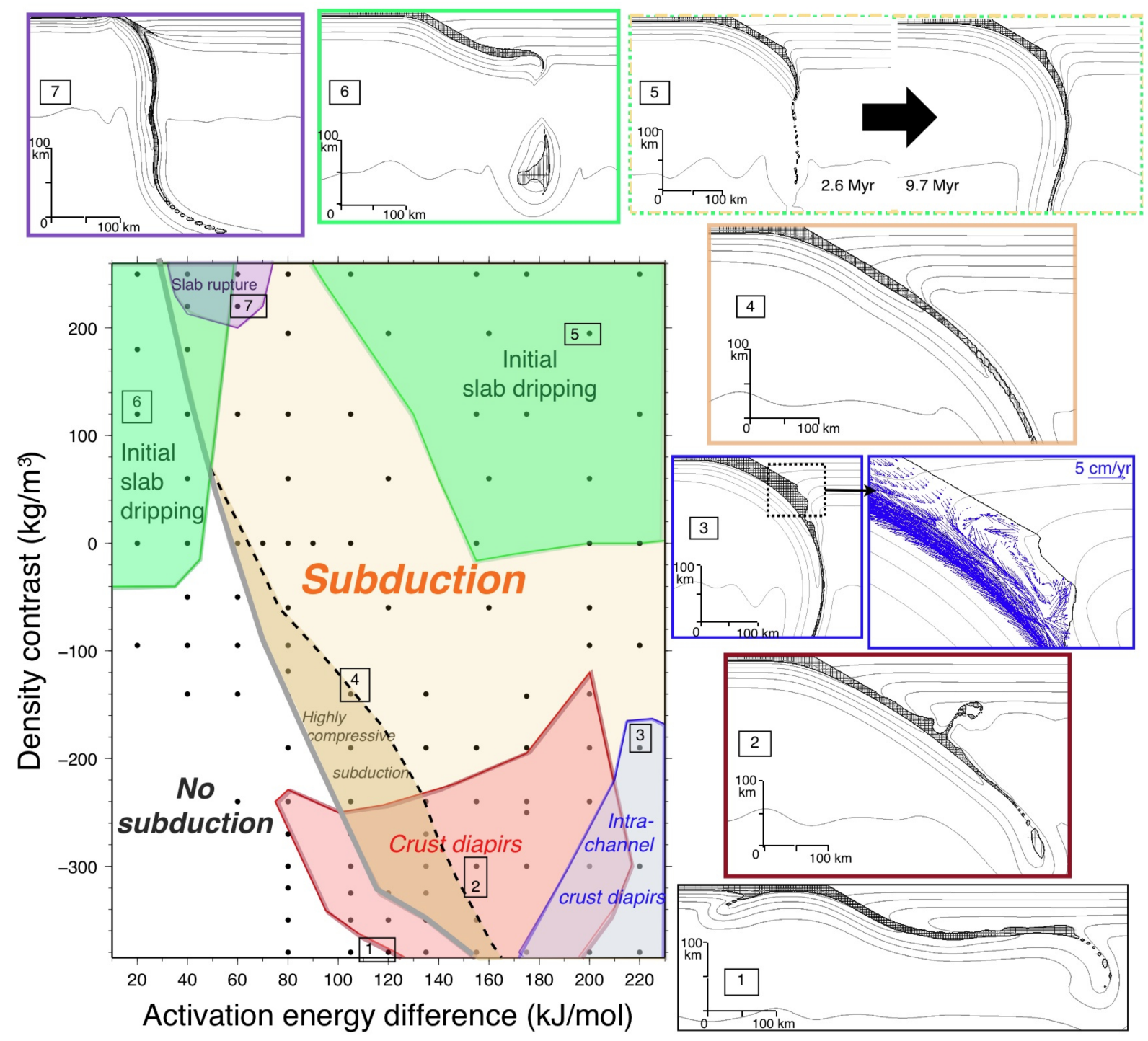

Figure 7: Subduction modes for a 20 Myr old incoming lithosphere as a function of the subducting crust buoyancy, $\Delta \rho_{c}$, and crust ductile weakening, $\Delta E_{a}$. Experiments are depicted by small solid black circles (Table 3 ). In insets (1) to (7) illustrating the different subduction regimes, isotherms are displayed every $200^{\circ} \mathrm{C}$, and the subducting crust by the grey-dashed area. (1) simulation S2-12a in Table 3; (2) simulation S2-15c; (3) simulation S2-22c; (4) simulation S2-10h; (5) simulation S2-20j; (6) simulation S2-2c; (7) simulation S2-6g. 
a. Partial coupling with crust diapirism $\Delta \mathrm{E}_{\mathrm{a}}=175 \mathrm{~kJ} / \mathrm{mol}, \quad \Delta \rho_{\mathrm{c}}=-300 \mathrm{~kg} / \mathrm{m}^{3}$
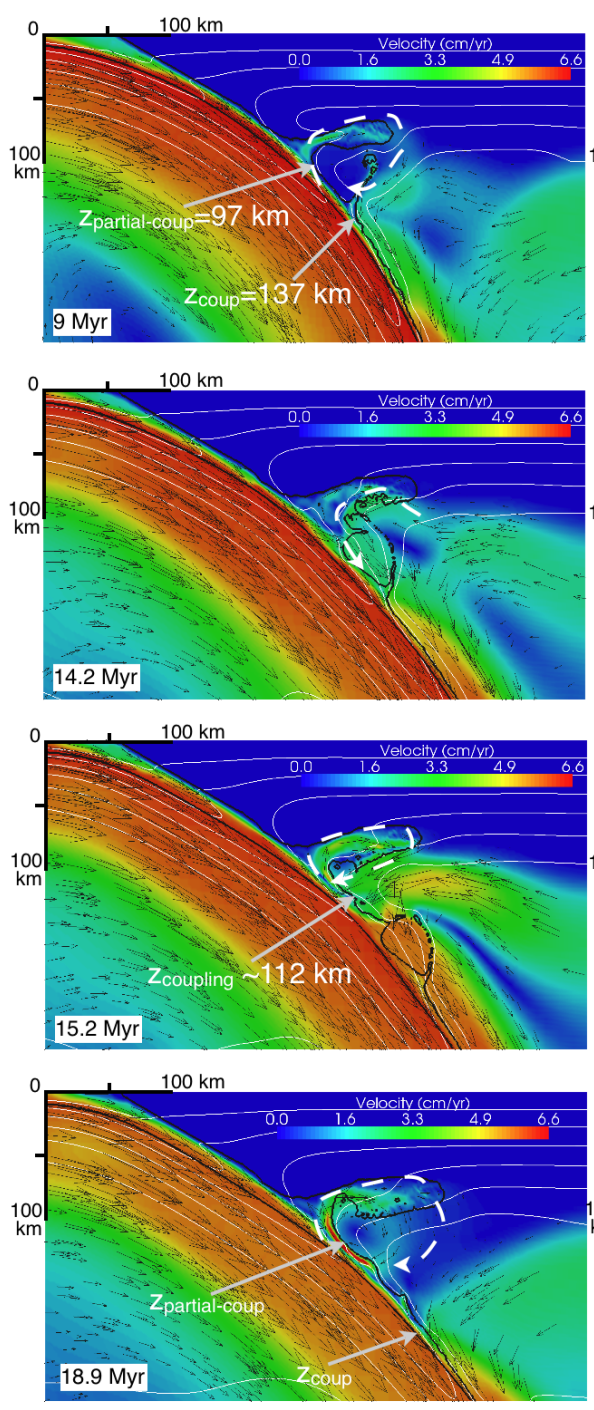

b. Partial coupling without crust diapirism $\Delta \mathrm{E}_{\mathrm{a}}=135 \mathrm{~kJ} / \mathrm{mol}, \quad \Delta \rho_{\mathrm{c}}=-190 \mathrm{~kg} / \mathrm{m}^{3}$
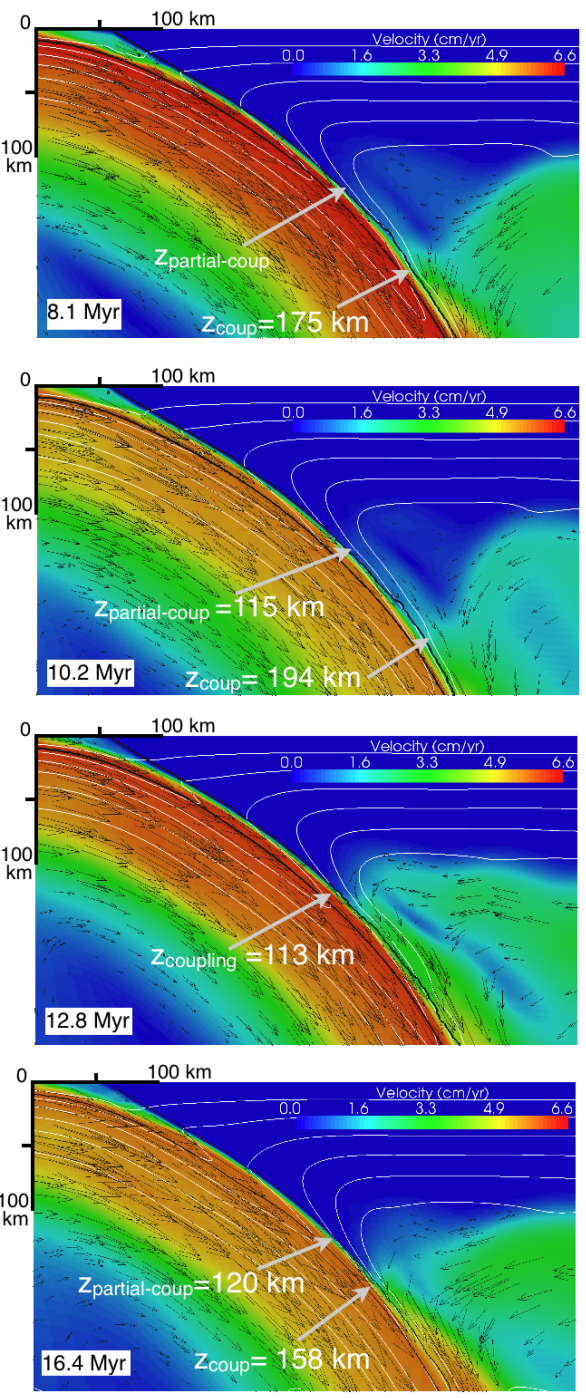

Figure 8: Evolution of the velocity field and thermal structure for a buoyant and weak subducting crust, when crust plumes form (panel a, simulation S2-13g, Table 3), or not (panel $\mathrm{b}$, simulation $\mathrm{S} 2-17 \mathrm{~b}$ ). One isotherm (white outline) every $200^{\circ} \mathrm{C}$. Within the thick black outline, crust content is higher than $49 \%$. The color scale refers to velocity magnitude, arrows depict velocity vectors. 


\section{a. $\mathbf{z}_{\text {coup }}$ depth at $10 \mathrm{Myr}$}

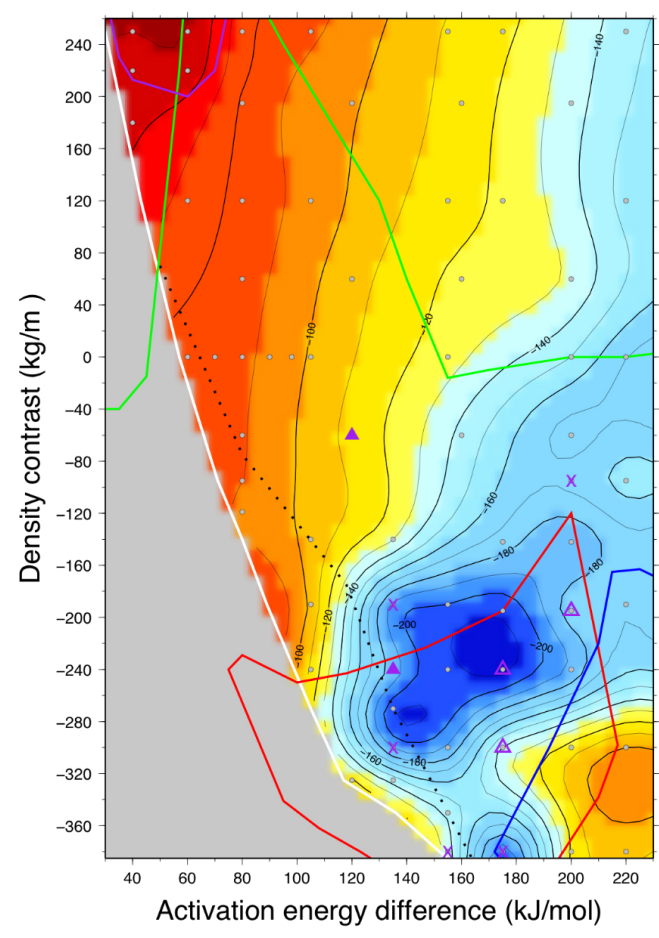

b. Minimum $\mathrm{z}_{\text {coup }}$ depth between $10 \mathrm{Myr}$ and 13.5 Myr

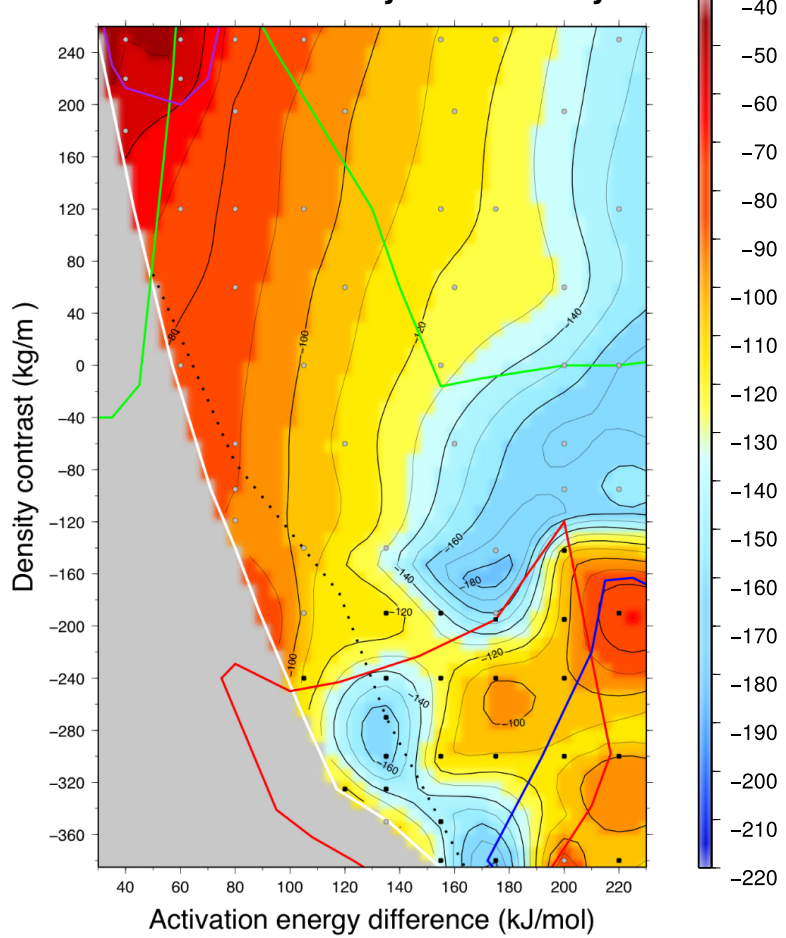

Figure 9: Maps of $z_{\text {coup }}$ simulated at different time steps for $A_{t}=20 \mathrm{Myr}$ as a function of crustal weakness, $\Delta E_{a}$, and buoyancy, $\Delta \rho_{c}$, with respect to mantle. Depth outlines are plotted every $10 \mathrm{~km}$. (a) $z_{\text {coup }}$ modelled after $10 \mathrm{Myr}$ of convergence. Experiments are depicted by grey-filled black circles. Passive water transfers and wet mantle melting estimate are computed in experiments depicted by purple symbols (see Fig. 10). Crosses: wet mantle welting extinction; solid triangles: stable hydrous melting; empty triangles: intermittent wet mantle melting. (b) Shallowest $z_{\text {coup }}$ depth obtained between 10 and 13.5 Myr. Experiments showing partial kinematic coupling are depicted by solid black circles. See Fig. 7 caption for the meaning of green, red, blue, purple and black-dashed thick lines. 
a. Limited but steadily high wet mantle melting

Water expelled

at $\mathrm{T}>980^{\circ} \mathrm{C}$ :
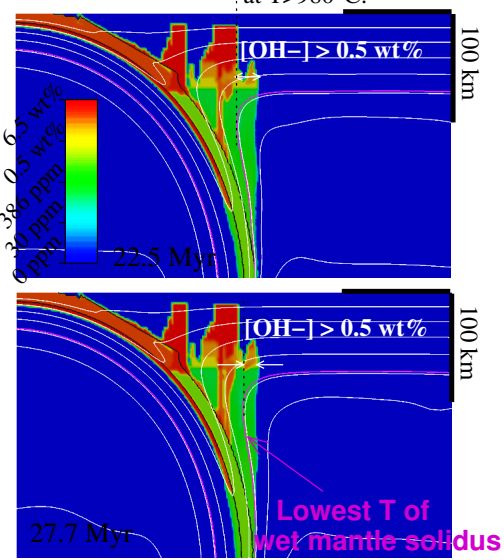

Simulation S2-20f

$\Delta \mathrm{E}_{\mathrm{a}}=200 \mathrm{~kJ} / \mathrm{mol}, \Delta \rho_{\mathrm{C}}=-95 \mathrm{~kg} / \mathrm{m}^{3}$ b. $\triangle$ intermittent magma supply to the volcanic front

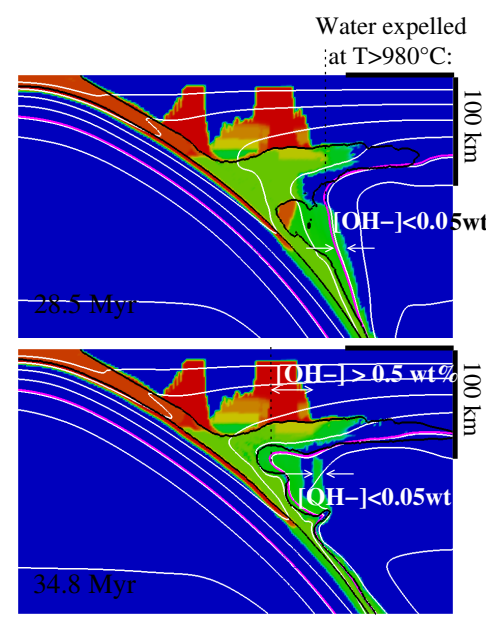

Simulation S2-17b

$\Delta \mathrm{E}_{\mathrm{a}}=175 \mathrm{~kJ} / \mathrm{mol}, \Delta \rho_{\mathrm{C}}=-300 \mathrm{~kg} / \mathrm{m}^{3}$ c. X Extinction of volcanic front activity sustained by mantle melting Water expelled $\vdots$ at $\mathrm{T}>980^{\circ} \mathrm{C}$ :

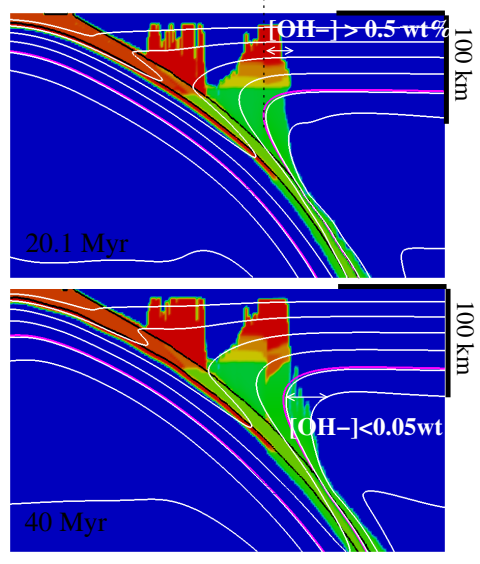

Simulation $\mathrm{S} 2-13 \mathrm{~g}$

$\Delta \mathrm{E}_{\mathrm{a}}=135 \mathrm{~kJ} / \mathrm{mol}, \Delta \rho_{\mathrm{C}}=-190 \mathrm{~kg} / \mathrm{m}^{3}$

Figure 10: Prediction of water amounts (labelled $\left[\mathrm{OH}^{-}\right]$) available in the mantle wedge to sustain mantle melting, for a $20 \mathrm{Myr}$ old downgoing plate. Purple symbols in headings refer to Fig. 9a. (a) Water absorbed in the mantle wedge at temperature exceeding the minimum wet solidus temperature $\left(980^{\circ} \mathrm{C}\right.$, pink isotherm) in amounts always $>0.5 \mathrm{wt} \%$ sufficient to allow continuous melting. (b) Water absorbed at $T>980^{\circ} \mathrm{C}$ in amounts strongly varying through time, temporarily very low and yielding discontinuous magmatism in the mantle wedge. (c) Progressive decrease through time of the water amount absorbed at $T>980^{\circ} C$, predicting mantle melting to vanish off. 


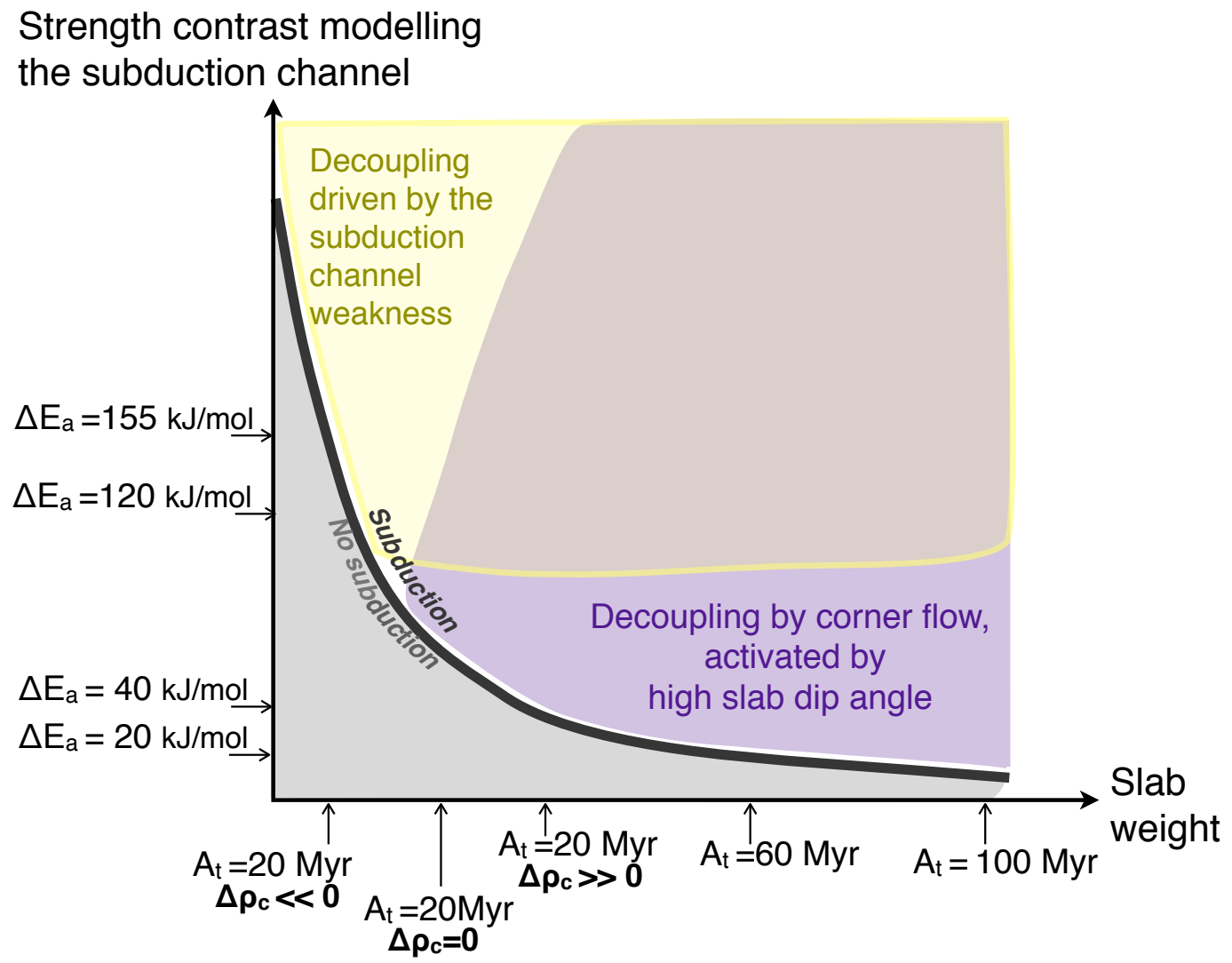

Figure 11: Schematic diagram illustrating the main mechanism controlling kinematic decoupling along the plate boundary, as a function of slab weight and the ductile strength of the subduction channel. 


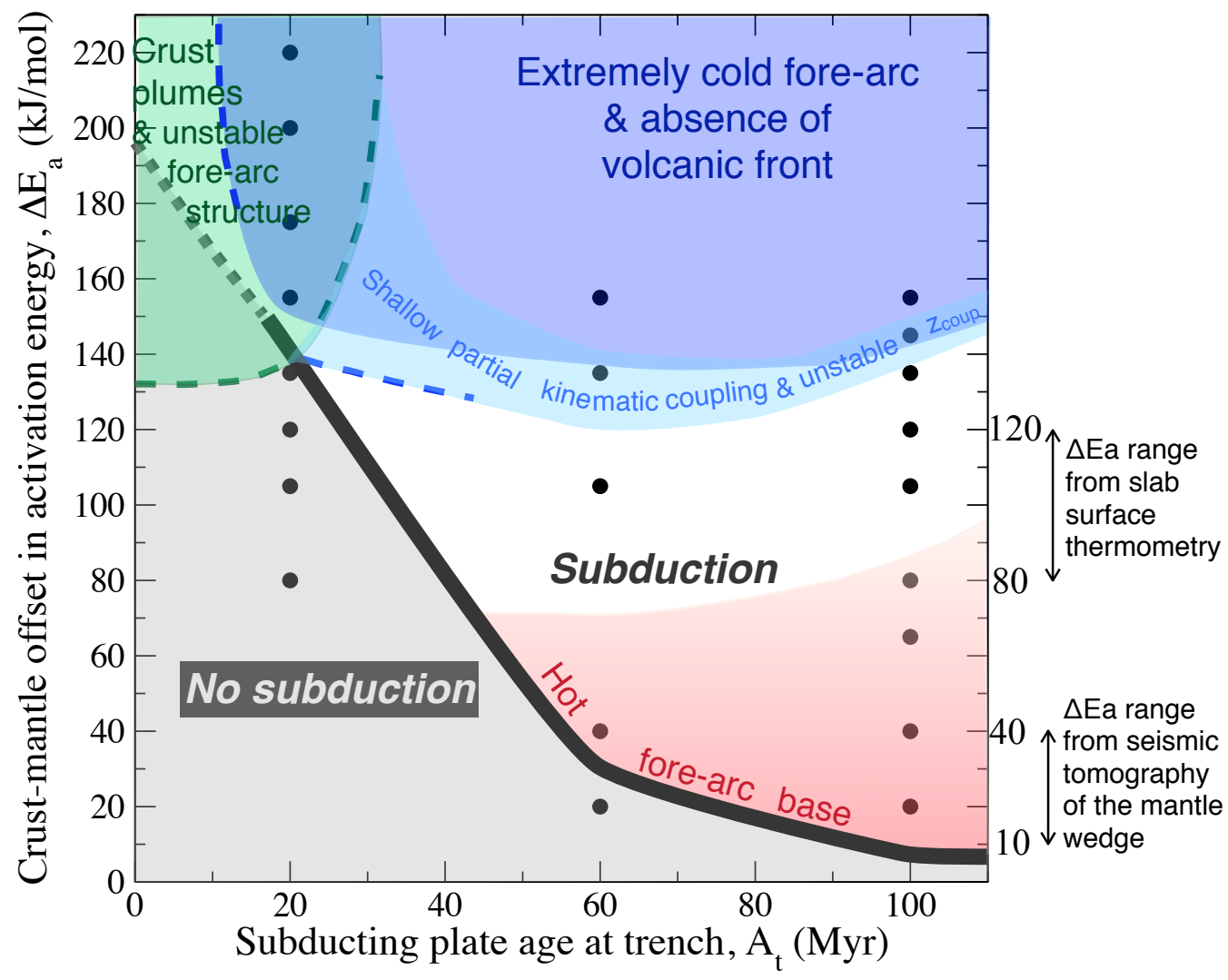

Figure 12: Subduction mode as a function of the incoming plate age and the contrast in ductile strength between crust and mantle, for a buoyant subducting crust $\left(\Delta \rho_{c}=-380 \mathrm{~kJ} / \mathrm{mol}\right)$ and a $100 \mathrm{~km}$ thick overriding plate. Numerical experiments are depicted by solid black circles (Table 3). The boundaries between the different subduction regimes are arbitrarily extended by dashed lines (unexplored domains). The red coloured shadding stands for the fore-arc heating by corner flow decreasing as $\Delta E_{a}$ is increased. 


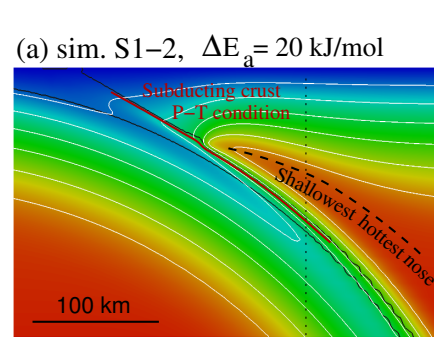

(b) $\operatorname{sim} . \mathrm{S} 1-14, \Delta \mathrm{E}=145 \mathrm{~kJ} / \mathrm{mol}$

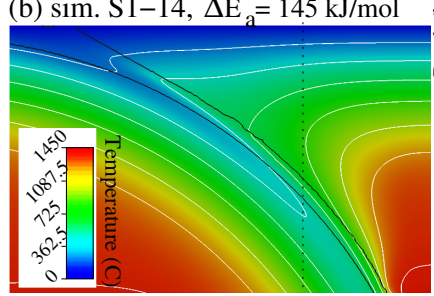

(c) $\operatorname{sim}$. S $1-8 \mathrm{~b}, \Delta \mathrm{E}_{\mathrm{a}}=80 \mathrm{~kJ} / \mathrm{mol}$
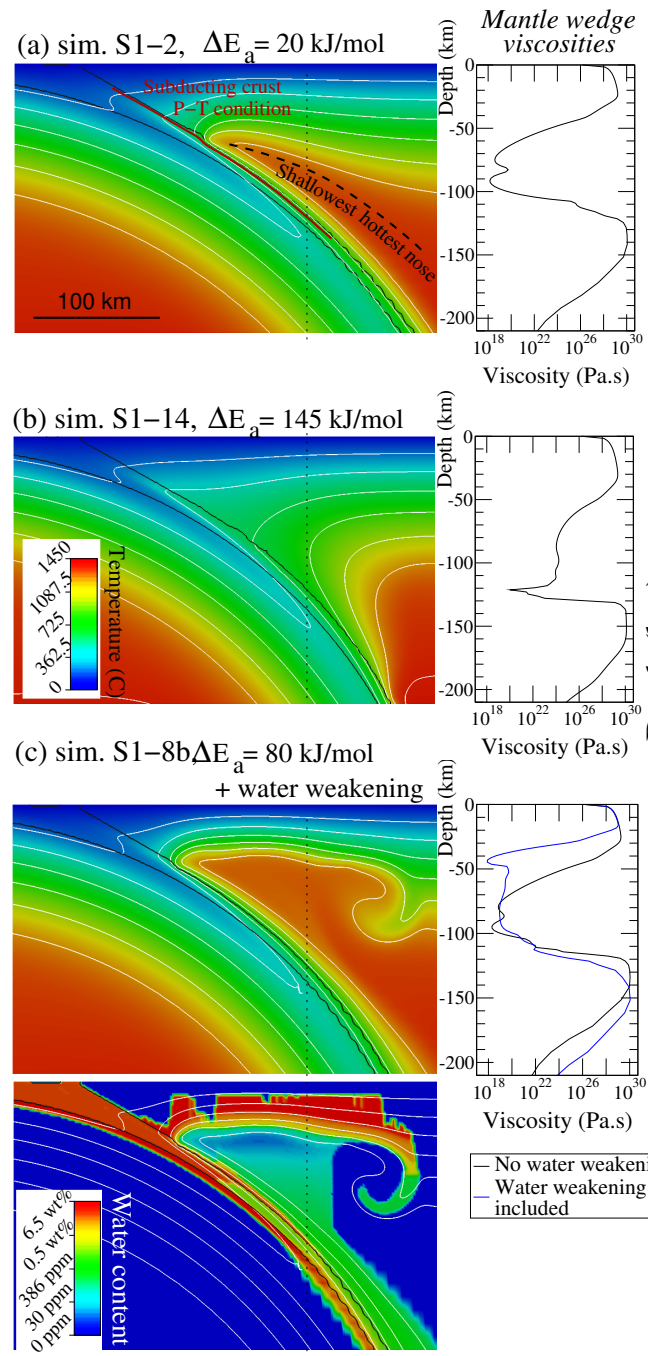

Viscosity (Pa.s)

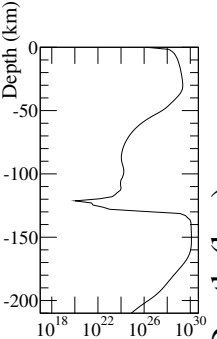

Viscosity (Pa.s)
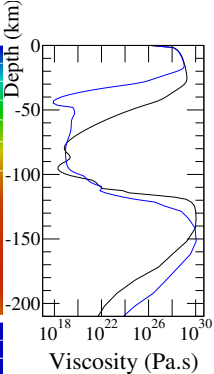

- No water weakening Water weakening
included

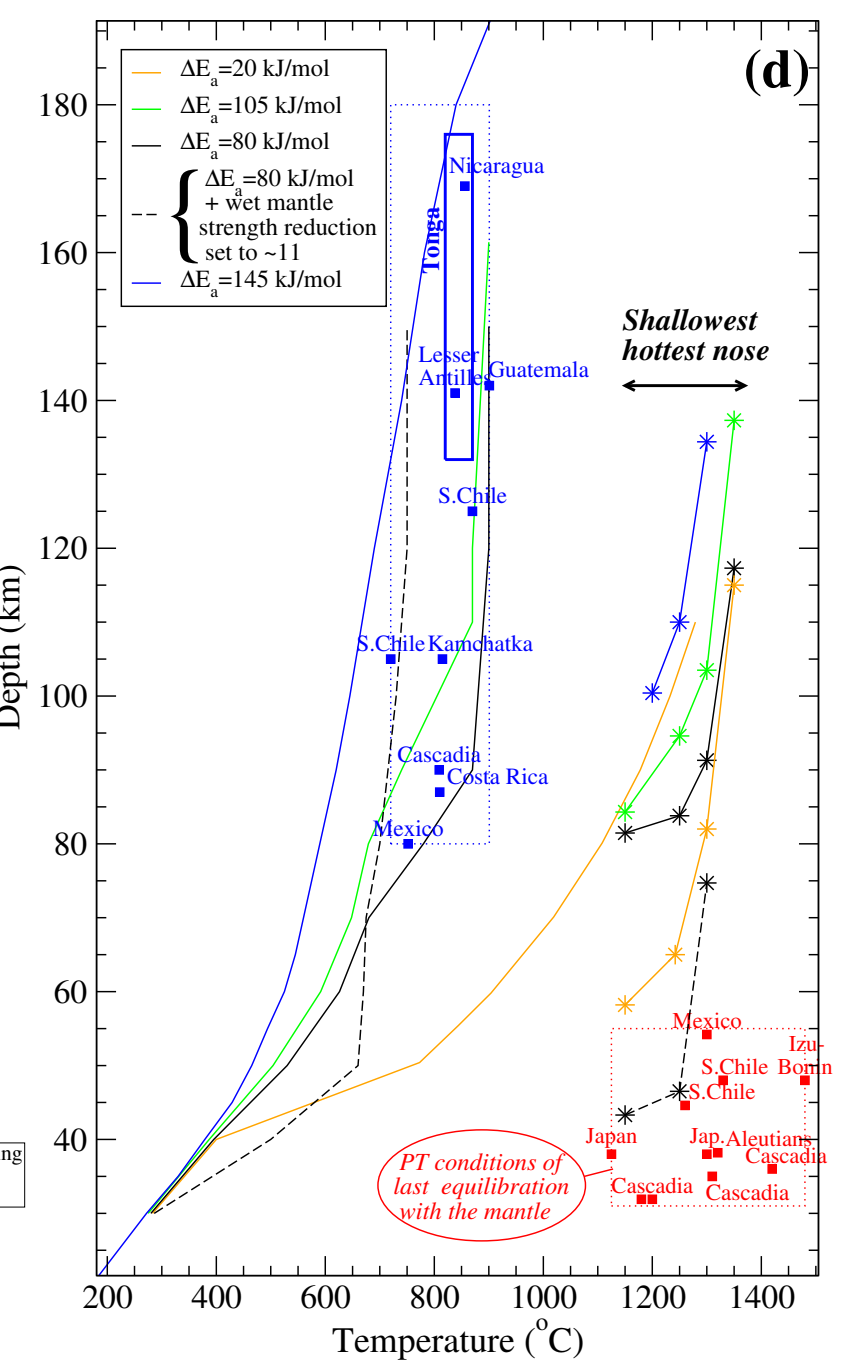

Figure 13: (a-c) Subduction thermal structures at steady-state as a function of $\Delta E_{a}$. One white isotherm every $200^{\circ} \mathrm{C}$. The black outline delimits the subducting crust. Thermal states modelled with $\Delta E_{a}=80 \mathrm{~kJ} / \mathrm{mol}$ and $\Delta E_{a}=105 \mathrm{~kJ} / \mathrm{mol}$ are displayed in Fig. 3a and 4c. Right panels diplay viscosity profiles along the dotted line depicted in left panels. (d) $P-T$ conditions modelled along the subducting crust surface (solid lines) compared to slab surface temperature estimated by geothermometry (Plank et al., 2009; Cooper et al., 2012; Watt et al., 2013) and sub-arc slab surface depth from Syracuse and Abers (2006) (blue solid squares, blue-dotted box). Lines with stars depict the hottest geotherm modelled in the mantle wedge, compared with conditions of last equilibration with the mantle of near-primary arc magmas (Tatsumi, 1981; Tatsumi et al., 1983; Bartels et al., 1991; Draper and Johnston, 1992; Falloon and Danyushevsky, 2000; Elkins Tanton et al., 2001; Grove et al., 2003; Hesse and Grove, 2003; Watt et al., 2013, red solid squares, red-dotted box). 
Table 1: Characteristics of numerical grids.

\begin{tabular}{l|c|c|c|c}
\hline Grid & LR & HRlim & HR & MHR \\
\hline Resolution $x \times z$ & $332 \times 90$ & $482 \times 129$ & $482 \times 151$ & $407 \times 119$ \\
\hline$\Delta x_{\min }(\mathrm{km})$ & 2.846 & 1.267 & 1.267 & 1.72 \\
imposed between $(\mathrm{km})$ & $1012<x<1397$ & $1004<x<1382$ & $1004<x<1382$ & $996<x<1389$ \\
$\Delta x_{\max }(\mathrm{km})$ & 9.51 & 9.51 & 10.4 & 10.6 \\
\hline$\Delta z_{\min }(\mathrm{km})$ & 2.268 & 1.266 & 1.266 & 1.656 \\
imposed for $(\mathrm{km})$ & $z>-116.1$ & $z>-102.0$ & $z>-136$ & $z>-142^{\mathrm{a}}$ \\
$\Delta z_{\max }(\mathrm{km})$ & 10.2 & 10.3 & 10.3 & 10.1 \\
\hline Oceanic crust & & & 6.94 & 8.33 \\
thickness $(\mathrm{km})$ & 6.94 & 6.94 & $5.76 \times 10^{6}$ & $3.24 \times 10^{6}$ \\
Total tracer number & $1.2544 \times 10^{6}$ & $5.76 \times 10^{6}$ & & \\
\hline
\end{tabular}

a for $A_{t}=60 \mathrm{Myr}$ and $A_{t}=100 \mathrm{Myr}, \Delta z_{\text {min }}$ is imposed for depth shallower than $250 \mathrm{~km}$ when $\Delta E_{a}>120 \mathrm{~kJ} / \mathrm{mol}$. 
Table 2: Parameter names and values.

\begin{tabular}{lcc}
\hline Parameter name & Symbol & Value \\
\hline Box height & $H_{0}$ & $555 \mathrm{~km}$ \\
Bottom temperature & $T_{b}$ & $1888 \mathrm{~K}$ \\
Surface temperature & $T_{s}$ & $273 \mathrm{~K}$ \\
Mantle density & $\rho_{m}$ & $3300 \mathrm{~kg} \cdot \mathrm{m}^{-3}$ \\
Density offset between crust and mantle & $\Delta \rho_{c}$ & $\Delta \rho_{c}=\rho_{c}-\rho_{m}$ \\
Crust density & $\rho_{c}$ & varying \\
Mantle radiogenic heat production & $A$ & $9.20 \times 10^{-8} \mathrm{~W}^{-m^{-3}}$ \\
Adiabatic gradient & $\left.\frac{\partial T}{\partial z}\right)_{a d i a b}$ & $0.45 \mathrm{~K}_{\mathrm{km}}^{-1}$ \\
Thermal diffusivity & $\kappa$ & $0.8 \times 10^{-6} \mathrm{~m}^{2} . \mathrm{s}^{-1}$ \\
Thermal expansion coefficient & $\alpha$ & $3.5 \times 10^{-5} \mathrm{~K}^{-1}$ \\
Heat capacity & $C_{p}$ & $0.971 \times 10^{3} \mathrm{~J} .(\mathrm{K} . \mathrm{kg})^{-1}$ \\
Activation energy for the mantle & $E_{a}^{m}$ & $465 \mathrm{~kJ} / \mathrm{mol}^{m}$ \\
Activation energy for the crust & $E_{a}^{c}$ & varying \\
Activation energy offset crust/mantle & $\Delta E_{a}$ & $\Delta E_{a}=E_{a}^{m}-E_{a}^{c}$ \\
Activation volume & $V_{a}$ & $1.7 \times 10^{-5} \mathrm{~m}^{3} / \mathrm{mol}^{c}$ \\
Pre-exponential factor in non-Newtonian rheology & $A_{0}$ & $339428.7 \mathrm{MPa}{ }^{-3} \cdot \mathrm{s}^{-1}$ \\
Dissipation number & $D i=\frac{\alpha g H_{0}}{C_{p}}$ & 0.196 \\
Gravity acceleration & $g$ & $9.81 \mathrm{~m} . \mathrm{s}^{-2}$ \\
Weak layer thickness & $h_{c}$ & $6.9 \mathrm{~km} \mathrm{or} 8.3 \mathrm{~km}$ \\
Convergence rate & $v_{c}$ & $6.5 \mathrm{~cm} / \mathrm{yr}$ \\
Subducting plate age at trench & $A_{t}$ & varying \\
Cohesive strength at $z=0$ & $\tau_{0}$ & $1 \mathrm{MPa}$ \\
Stress exponent in the viscous rheology & $n$ & 3 \\
Stress exponent in the brittle rheology & $n_{p}$ & 30 \\
Yield stress increase with depth (mantle) & $\gamma_{m}$ & 1.6 \\
Yield stress increase with depth (crust) & $\gamma_{c}$ & 0.065 \\
\hline
\end{tabular}


Table 3: Simulation list. (continued on next pages)

\begin{tabular}{cccccccc}
\hline Simulation & $\begin{array}{c}A_{t} \\
\mathrm{Myr}\end{array}$ & $\begin{array}{c}\Delta E_{a} \\
\mathrm{~kJ} / \mathrm{mol}\end{array}$ & $\begin{array}{c}E_{a}^{c} \\
\mathrm{~kJ} / \mathrm{mol}\end{array}$ & $\begin{array}{c}\Delta \rho_{c} \\
\mathrm{~kg} / \mathrm{m}^{3}\end{array}$ & $\begin{array}{c}\rho_{c} \\
\mathrm{~kg} / \mathrm{m}^{3}\end{array}$ & $\begin{array}{c}\text { Numerical } \\
\text { grid }\end{array}$ & $\begin{array}{c}z_{\text {dec }}{ }^{\mathrm{a}} \\
\mathrm{km}\end{array}$ \\
\hline $\mathrm{S} 1-2$ & 100 & 20 & 445 & -380 & 2920 & MHR & 59.8 \\
$\mathrm{~S} 1-4$ & 100 & 40 & 425 & -380 & 2920 & MHR & 63 \\
$\mathrm{~S} 1-6$ & 100 & 65 & 400 & -380 & 2920 & MHR & 74 \\
$\mathrm{~S} 1-8$ & 100 & 80 & 385 & -380 & 2920 & MHR & 81.7 \\
$\mathrm{~S} 1-8 \mathrm{~b}^{\mathrm{e}}$ & 100 & 80 & 385 & -380 & 2920 & $\mathrm{MHR}$ & 48 \\
$\mathrm{~S} 1-10 \mathrm{a}$ & 100 & 105 & 360 & -380 & 2920 & $\mathrm{LR}$ & $80 \mathrm{~km}^{\mathrm{b}}$ \\
$\mathrm{S} 1-10 \mathrm{~b}$ & 100 & 105 & 360 & -380 & 2920 & HRlim & $102^{\mathrm{b}}$ \\
$\mathrm{S} 1-10 \mathrm{c}$ & 100 & 105 & 360 & -380 & 2920 & HR & 114 \\
$\mathrm{~S} 1-10 \mathrm{~d}$ & 100 & 105 & 360 & -380 & 2920 & MHR & 109 \\
$\mathrm{~S} 1-12$ & 100 & 120 & 345 & -380 & 2920 & MHR & 135.3 \\
$\mathrm{~S} 1-13$ & 100 & 135 & 385 & -380 & 2920 & MHR & 166 \\
$\mathrm{~S} 1-14^{\mathrm{c}}$ & 100 & 145 & 155 & -380 & 2920 & MHR & $162-200^{\mathrm{b}}$ \\
$\mathrm{S} 1-15^{\mathrm{c}}$ & 100 & 155 & 310 & -380 & 2920 & MHR & $250^{\mathrm{b}}$ \\
$\mathrm{S} 6-2$ & 60 & 20 & 445 & -380 & 2920 & MHR & $-\mathrm{d}$ \\
$\mathrm{S} 6-4$ & 60 & 40 & 425 & -380 & 2920 & MHR & 65.8 \\
$\mathrm{~S} 6-10$ & 60 & 105 & 360 & -380 & 2920 & MHR & 118.5 \\
$\mathrm{~S} 6-13^{\mathrm{c}}$ & 60 & 135 & 385 & -380 & 2920 & MHR & $124-219^{\mathrm{b}}$ \\
$\mathrm{S} 6-15$ & 60 & 155 & 310 & -380 & 2920 & MHR & $250^{\mathrm{b}}$ \\
$\mathrm{S} 2-2 \mathrm{a}$ & 20 & 20 & 445 & -95 & 3205 & MHR & $-\mathrm{d}$ \\
$\mathrm{S} 2-2 \mathrm{~b}$ & 20 & 20 & 445 & 0 & 3300 & MHR & $-\mathrm{d}$ \\
$\mathrm{S} 2-2 \mathrm{c}$ & 20 & 20 & 445 & 120 & 3420 & MHR & $-\mathrm{d}$ \\
$\mathrm{S} 2-2 \mathrm{~d}$ & 20 & 20 & 445 & 180 & 3480 & MHR & $-\mathrm{d}$ \\
\hline
\end{tabular}




\begin{tabular}{cccccccc}
\hline Simulation & $A_{t}$ & $\Delta E_{a}$ & $E_{a}^{c}$ & $\Delta \rho_{c}$ & $\rho_{c}$ & Num. grid & $z_{\text {dec }}{ }^{\mathrm{a}}$ \\
\hline S2-2e & 20 & 20 & 445 & 250 & 3550 & MHR & $-\mathrm{d}$ \\
S2-4a & 20 & 40 & 425 & -140 & 3160 & MHR & $-\mathrm{d}$ \\
S2-4b & 20 & 40 & 425 & -95 & 3205 & MHR & $-\mathrm{d}$ \\
S2-4c & 20 & 40 & 425 & -50 & 3250 & MHR & $-\mathrm{d}$ \\
S2-4d & 20 & 40 & 425 & 0 & 3300 & MHR & $-\mathrm{d}$ \\
S2-4e & 20 & 40 & 425 & 60 & 3360 & MHR & $-\mathrm{d}$ \\
S2-4f & 20 & 40 & 425 & 120 & 3420 & MHR & $-\mathrm{d}$ \\
S2-4g & 20 & 40 & 425 & 180 & 3480 & MHR & 58.1 \\
S2-4h & 20 & 40 & 425 & 220 & 3520 & MHR & 55 \\
S2-4i & 20 & 40 & 425 & 250 & 3550 & MHR & 50 \\
S2-6a & 20 & 60 & 405 & -240 & 3060 & MHR & $-\mathrm{d}$ \\
S2-6b & 20 & 60 & 405 & -140 & 3160 & MHR & $-\mathrm{d}$ \\
S2-6c & 20 & 60 & 405 & -95 & 3205 & MHR & $-\mathrm{d}$ \\
S2-6d & 20 & 60 & 405 & -50 & 3250 & MHR & $-\mathrm{d}$ \\
S2-6e & 20 & 60 & 405 & 0 & 3300 & MHR & 84 \\
S2-6f & 20 & 60 & 405 & 120 & 3420 & MHR & 72.9 \\
S2-6g & 20 & 60 & 405 & 220 & 3520 & MHR & 53.6 \\
S2-6h & 20 & 60 & 405 & 250 & 3550 & MHR & 50.5 \\
S2-7 & 20 & 70 & 395 & 0 & 3300 & MHR & 83.7 \\
S2-8a & 20 & 80 & 385 & -380 & 2920 & MHR & $-\mathrm{d}$ \\
S2-8b & 20 & 80 & 385 & -350 & 2950 & MHR & $-\mathrm{d}$ \\
S2-8c & 20 & 80 & 385 & -320 & 2980 & MHR & $-\mathrm{d}$ \\
S2-8d & 20 & 80 & 385 & -300 & 3000 & MHR & $-\mathrm{d}$ \\
S2-8e & 20 & 80 & 385 & -270 & 3030 & MHR & $-\mathrm{d}$ \\
S2-8f & 20 & 80 & 385 & -240 & 3060 & MHR & $-\mathrm{d}$ \\
\hline & & & & & & &
\end{tabular}




\begin{tabular}{cccccccc}
\hline Simulation & $A_{t}$ & $\Delta E_{a}$ & $E_{a}^{c}$ & $\Delta \rho_{c}$ & $\rho_{c}$ & Num. grid & $z_{d e c}{ }^{\mathrm{a}}$ \\
\hline $\mathrm{S} 2-8 \mathrm{~g}$ & 20 & 80 & 385 & -195 & 3105 & MHR & $-\mathrm{d}$ \\
$\mathrm{S} 2-8 \mathrm{~h}$ & 20 & 80 & 385 & -140 & 3160 & MHR & $-\mathrm{d}$ \\
$\mathrm{S} 2-8 \mathrm{i}$ & 20 & 80 & 385 & -120 & 3180 & MHR & 83.4 \\
S2-8j & 20 & 80 & 385 & -95 & 3205 & MHR & 89.7 \\
S2-8k & 20 & 80 & 385 & -60 & 3240 & MHR & 89.1 \\
S2-8l & 20 & 80 & 385 & 0 & 3300 & MHR & 87.6 \\
S2-8m & 20 & 80 & 385 & 60 & 3360 & MHR & 85.6 \\
S2-8n & 20 & 80 & 385 & 120 & 3420 & MHR & 83.4 \\
S2-8o & 20 & 80 & 385 & 195 & 3495 & MHR & 81.6 \\
S2-8p & 20 & 80 & 385 & 250 & 3550 & MHR & 75.7 \\
S2-9a & 20 & 90 & 375 & 0 & 3300 & MHR & 92.9 \\
S2-10a & 20 & 105 & 360 & -380 & 2920 & MHR & $-\mathrm{d}$ \\
S2-10b & 20 & 105 & 360 & -350 & 2950 & MHR & $-\mathrm{d}$ \\
S2-10c & 20 & 105 & 360 & -320 & 2980 & MHR & $-\mathrm{d}$ \\
S2-10d & 20 & 105 & 360 & -300 & 3000 & MHR & $-\mathrm{d}$ \\
S2-10e & 20 & 105 & 360 & -270 & 3030 & MHR & $-\mathrm{d}$ \\
S2-10f & 20 & 105 & 360 & -240 & 3060 & MHR & 111.3 \\
S2-10g & 20 & 105 & 360 & -190 & 3110 & MHR & 101.6 \\
S2-10h & 20 & 105 & 360 & -140 & 3160 & MHR & 103.6 \\
S2-10i & 20 & 105 & 360 & 0 & 3300 & MHR & 101 \\
S2-10j & 20 & 105 & 360 & 120 & 3420 & MHR & 93.8 \\
S2-10k & 20 & 105 & 360 & 250 & 3550 & MHR & 88.2 \\
S2-12a & 20 & 120 & 345 & -380 & 2920 & MHR & $-\mathrm{d}$ \\
S2-12b & 20 & 120 & 345 & -350 & 2950 & MHR & $-\mathrm{d}$ \\
S2-12c & 20 & 120 & 345 & -325 & 2975 & MHR & 119 \\
\hline
\end{tabular}




\begin{tabular}{cccccccc}
\hline Simulation & $A_{t}$ & $\Delta E_{a}$ & $E_{a}^{c}$ & $\Delta \rho_{c}$ & $\rho_{c}$ & Num. grid & $z_{d e c}{ }^{\mathrm{a}}$ \\
\hline $\mathrm{S} 2-12 \mathrm{~d}^{\mathrm{c}}$ & 20 & 120 & 345 & -60 & 3240 & MHR & 113.3 \\
$\mathrm{~S} 2-12 \mathrm{e}$ & 20 & 120 & 345 & 60 & 3360 & MHR & 106.4 \\
$\mathrm{~S} 2-12 \mathrm{f}$ & 20 & 120 & 345 & 195 & 3495 & MHR & 98.8 \\
$\mathrm{~S} 2-13 \mathrm{a}$ & 20 & 135 & 330 & -380 & 2920 & MHR & $-\mathrm{d}$ \\
$\mathrm{S} 2-13 \mathrm{~b}$ & 20 & 135 & 330 & -350 & 2950 & MHR & $-\mathrm{d}$ \\
$\mathrm{S} 2-13 \mathrm{c}$ & 20 & 135 & 330 & -325 & 2975 & MHR & 145 \\
$\mathrm{~S} 2-13 \mathrm{~d}^{\mathrm{c}}$ & 20 & 135 & 330 & -300 & 3000 & MHR & 192 \\
$\mathrm{~S} 2-13 \mathrm{e}$ & 20 & 135 & 330 & -270 & 3030 & MHR & 209 \\
$\mathrm{~S} 2-13 \mathrm{fc}^{\mathrm{c}}$ & 20 & 135 & 330 & -240 & 3060 & MHR & 183 \\
$\mathrm{~S} 2-13 \mathrm{~g}^{\mathrm{c}}$ & 20 & 135 & 330 & -190 & 3110 & MHR & 194 \\
$\mathrm{~S} 2-13 \mathrm{~h}$ & 20 & 135 & 330 & -140 & 3160 & MHR & 128.7 \\
$\mathrm{~S} 2-15 \mathrm{a}^{\mathrm{c}}$ & 20 & 155 & 310 & -380 & 2920 & MHR & 133 \\
$\mathrm{~S} 2-15 \mathrm{~b}$ & 20 & 155 & 310 & -350 & 2950 & MHR & 142 \\
$\mathrm{~S} 2-15 \mathrm{c}$ & 20 & 155 & 310 & -300 & 3000 & MHR & 189 \\
$\mathrm{~S} 2-15 \mathrm{~d}$ & 20 & 155 & 310 & -240 & 3060 & MHR & 207 \\
$\mathrm{~S} 2-15 \mathrm{e}$ & 20 & 155 & 310 & -190 & 3110 & MHR & 200 \\
$\mathrm{~S} 2-15 \mathrm{f}$ & 20 & 155 & 310 & 0 & 3300 & MHR & 126.2 \\
$\mathrm{~S} 2-15 \mathrm{~g}$ & 20 & 155 & 310 & 120 & 3420 & MHR & 116 \\
$\mathrm{~S} 2-15 \mathrm{~h}$ & 20 & 155 & 310 & 250 & 3550 & MHR & 111 \\
$\mathrm{~S} 2-16 \mathrm{a}$ & 20 & 160 & 305 & -60 & 3240 & MHR & 143.2 \\
$\mathrm{~S} 2-16 \mathrm{~b}$ & 20 & 160 & 305 & 60 & 3360 & MHR & 122.7 \\
$\mathrm{~S} 2-17 \mathrm{a}^{\mathrm{c}}$ & 20 & 175 & 290 & -380 & 2920 & MHR & 201.4 \\
$\mathrm{~S} 2-17 \mathrm{~b}^{\mathrm{c}}$ & 20 & 175 & 290 & -300 & 3000 & MHR & 137.2 \\
$\mathrm{~S} 2-17 \mathrm{c}^{\mathrm{c}}$ & 20 & 175 & 290 & -240 & 3060 & MHR & $250^{\mathrm{b}}$ \\
$\mathrm{S} 2-17 \mathrm{~d}$ & 20 & 175 & 290 & -195 & 3105 & MHR & 207 \\
\hline
\end{tabular}




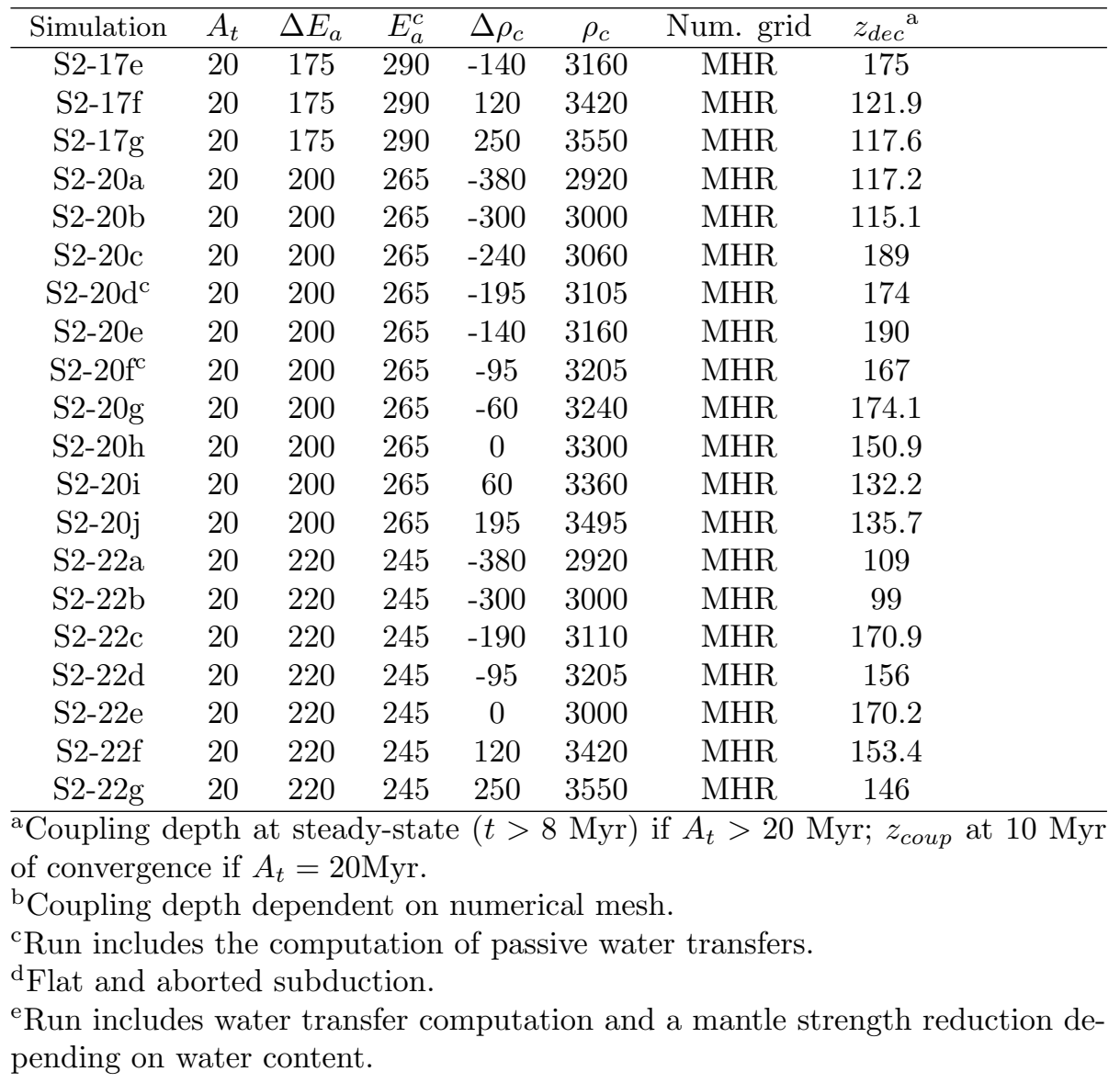

